\title{
Natural Polymeric Scaffolds in Bone Regeneration
}

\author{
Miriam Filippi ${ }^{1,2}$, Gordian Born ${ }^{1}$, Mansoor Chaaban ${ }^{2}$ and Arnaud Scherberich ${ }^{1,2 *}$ \\ 1 Department of Biomedical Engineering, University of Basel, Basel, Switzerland, ${ }^{2}$ Department of Biomedicine, University \\ Hospital Basel, University of Basel, Basel, Switzerland
}

\section{OPEN ACCESS}

Edited by:

Chiara Tonda-Turo,

Politecnico di Torino, Italy

Reviewed by:

Elena Jones,

University of Leeds, United Kingdom

Francesco Baino,

Politecnico di Torino, Italy

${ }^{*}$ Correspondence:

Arnaud Scherberich

arnaud.scherberich@usb.ch

Specialty section:

This article was submitted to

Tissue Engineering and Regenerative

Medicine,

a section of the journal

Frontiers in Bioengineering and

Biotechnology

Received: 05 February 2020

Accepted: 23 April 2020

Published: 21 May 2020

Citation:

Filippi M, Born G, Chaaban M and Scherberich A (2020) Natural

Polymeric Scaffolds in Bone

Regeneration.

Front. Bioeng. Biotechnol. 8:474.

doi: 10.3389/fbioe.2020.00474
Despite considerable advances in microsurgical techniques over the past decades, bone tissue remains a challenging arena to obtain a satisfying functional and structural restoration after damage. Through the production of substituting materials mimicking the physical and biological properties of the healthy tissue, tissue engineering strategies address an urgent clinical need for therapeutic alternatives to bone autografts. By virtue of their structural versatility, polymers have a predominant role in generating the biodegradable matrices that hold the cells in situ to sustain the growth of new tissue until integration into the transplantation area (i.e., scaffolds). As compared to synthetic ones, polymers of natural origin generally present superior biocompatibility and bioactivity. Their assembly and further engineering give rise to a wide plethora of advanced supporting materials, accounting for systems based on hydrogels or scaffolds with either fibrous or porous architecture. The present review offers an overview of the various types of natural polymers currently adopted in bone tissue engineering, describing their manufacturing techniques and procedures of functionalization with active biomolecules, and listing the advantages and disadvantages in their respective use in order to critically compare their actual applicability potential. Their combination to other classes of materials (such as micro and nanomaterials) and other innovative strategies to reproduce physiological bone microenvironments in a more faithful way are also illustrated. The regeneration outcomes achieved in vitro and in vivo when the scaffolds are enriched with different cell types, as well as the preliminary clinical applications are presented, before the prospects in this research field are finally discussed. The collection of studies herein considered confirms that advances in natural polymer research will be determinant in designing translatable materials for efficient tissue regeneration with forthcoming impact expected in the treatment of bone defects.

Keywords: natural polymer, scaffold, bone tissue, regeneration, tissue engineering

\section{INTRODUCTION}

Bone is an essential and multifunctional organ. While providing weight-bearing sustainment and assisting locomotion, the 206 bones in the adult human body have other defined biological roles, such as: generation of blood cells (haematopoiesis), physical protection of vital organs like brain or heart, and storage of minerals and growth factors (Clarke, 2008). Bone is constantly remodeled in physiological conditions and presents a strong regenerative capacity to react to fractures. However, in case of bone tumor removal, traumas with extensive defects or infections, the bone repair process 
can be impaired such that the damaged area cannot fully and spontaneously regenerate. Especially, when the defect size overcomes the healing capacity, a surgical intervention is needed. Such critical size bone defects are a clinical problem affecting millions of people worldwide, such that autologous bone graft is the second most commonly transplanted tissue after blood. Beyond the implantation of metallic prostheses, bone allo- or auto-grafts are indeed the main available therapeutic solutions for large bone defects (Laurencin et al., 2006; Calori et al., 2011). On one side, thanks to the presence of growth factors, bone material, and osteogenic cells, autologous grafts have excellent osteoinductive and osteoconductive features. Accounting for $\sim 58 \%$ of bone substitutes, autografts remain the gold standard for small defect reconstruction, but are also associated with a number of drawbacks, like infections, bleeding, limited amount of donor bone tissue, the need for a second surgery site for bone graft harvest, donor site morbidity, and chronic pain. On the other side, $\sim 34 \%$ of the bone substitutes have allogenic origin (often derived from cadavers). Despite being available in various forms and size, and free of morbidity issues, the allografts can cause infectious disease transmission and immunological rejection. Moreover, the sterilization procedure impairs the biological and mechanical properties of the graft (Blokhuis and Arts, 2011).

Novel strategies for the treatment and regeneration of bone tissue are offered by Tissue Engineering (TE), which aims at recovering, maintaining, and improving functions of damaged organs starting from a pool of regenerative cells, capable of both self-renewal, and differentiation in other cell types. Recent breakthroughs in the biology of stem cells (SCs), especially in relation to their trophic, regenerative and immunomodulatory functions, have raised tremendous enthusiasm in the development of innovative therapeutic solutions. Besides stem and progenitor cells, the backbone of TE relies on the investigation and optimization of cell stimulation strategies, and on the design of supporting materials (Reddy and Reddy, 2018). Thus far, several kinds of biodegradable matrices (i.e., scaffolds) have been developed to hold the regenerative cells in situ, re-create their biological microenvironments and sustain the growth of new tissue until integration into the transplantation area. SCs sense mechanical and biochemical signals from the niche they are located in Discher et al. (2009), such that their functional cues are orchestrated by a variety of interactions and factors, including the influence by other cells, soluble factors, and extracellular matrix (ECM). A better understanding of the complex and dynamic regulation of the cell fate specification would enable to precisely manipulate the phenotype and harness SCs for effective regenerative medicine.

However, as a composite material where hydroxyapatite (HA) crystals are dispersed into a collagen fiber matrix (Venugopal et al., 2010; Gardin et al., 2012), bone is a challenging tissue to engineer especially because of its complex hierarchical structure and dense vascularization (Logeart-Avramoglou et al., 2005; Genova et al., 2016). The first generation of synthetic bone grafts was based on metals and alloys (Ficai et al., 2011). Despite being widely used for their reproducibility and availability, such bio-inert bone implants constituted of alumina and stainless steel possess certain disadvantages, including poor integration and stiffness mismatch into the host bone, encapsulation into fibrous tissue, release of wear debris, lack of bioactivity, and bio-resorption (Ficai et al., 2011; Guarino et al., 2012). Other materials like polymers and bioactive ceramics were thus introduced to manufacture pure scaffolds first (Ficai et al., 2011; Guarino et al., 2012) and then composite ones (Sahoo et al., 2013). In composite ceramics-polymer scaffolds, the flexibility and resorption of the polymeric texture were combined to the mechanical and osteoconductive properties of ceramics (Sahoo et al., 2013). Finally, growth factors, bone morphogenetic proteins and osteogenic cells were added to increase the biological performance of the composite scaffolds (Ficai et al., 2011). In this context, the matrix of composite scaffolds can be based on polymers of either synthetic or natural origin. Since the synthetic polymers display lower biocompatibility, bioactivity, and amount of cell adhesion sites, the current research focus has shifted to the natural ones. Because of their similarity to the elements of the native ECM in the body, natural polymers have become a predominant source for the manufacturing of matrices that faithfully mimic the biological environments. Their controlled assembly can give rise to a platform of advanced supporting materials, generating systems based on hydrogels or scaffolds with customizable fibrous and/or porous architecture (Armentano et al., 2010; Wagoner Johnson and Herschler, 2011; Bonani et al., 2018).

Consisting of proteins (like collagen, silk, fibrin gels, and soy) or polysaccharides (like alginate, chitin/chitosan, starch, and hyaluronic acid derivatives) (Sell et al., 2010), natural polymers often show limited mechanical properties, immunogenic potential, or insufficient supply (Armentano et al., 2010; Swetha et al., 2010; Wagoner Johnson and Herschler, 2011). Therefore, the search for suitable materials and innovative strategies to efficiently reproduce a bone microenvironment is constantly active (Stevens, 2008; Holzwarth and Ma, 2011), and novel formulations are developed and tested to improve their in vivo performance (Giannoudis et al., 2005; Yunus Basha et al., 2015).

In this review, we present an overview of the various tissue constructs based on natural polymers currently developed for Bone Tissue Engineering (BTE), describing the manufacturing techniques, procedures of functionalization with bioactive molecules and their in vitro and in vivo regenerative outcomes. Finally, innovative perspectives to more faithfully mimic physiological bone microenvironments are discussed.

\section{BONE MORPHOLOGY}

To select the most appropriate biomaterial, the knowledge of the physicochemical architecture of native bone along with pertinent biomechanical features is critical. Some physico-mechanical properties of the natural bone and main BTE biomaterials are reported in Table 1.

\section{Matrix Composition}

Bone is a highly specialized connective tissue with a complex and precisely organized structure (Lafon et al., 2008; Ren et al., 2015; Arakawa et al., 2017; Lopes et al., 2018; Unal et al., 2018). From a chemical point of view, bone matrix contains around $65 \mathrm{wt}$. 
TABLE 1 | Physico-mechanical properties of natural bone and BTE biomaterials.

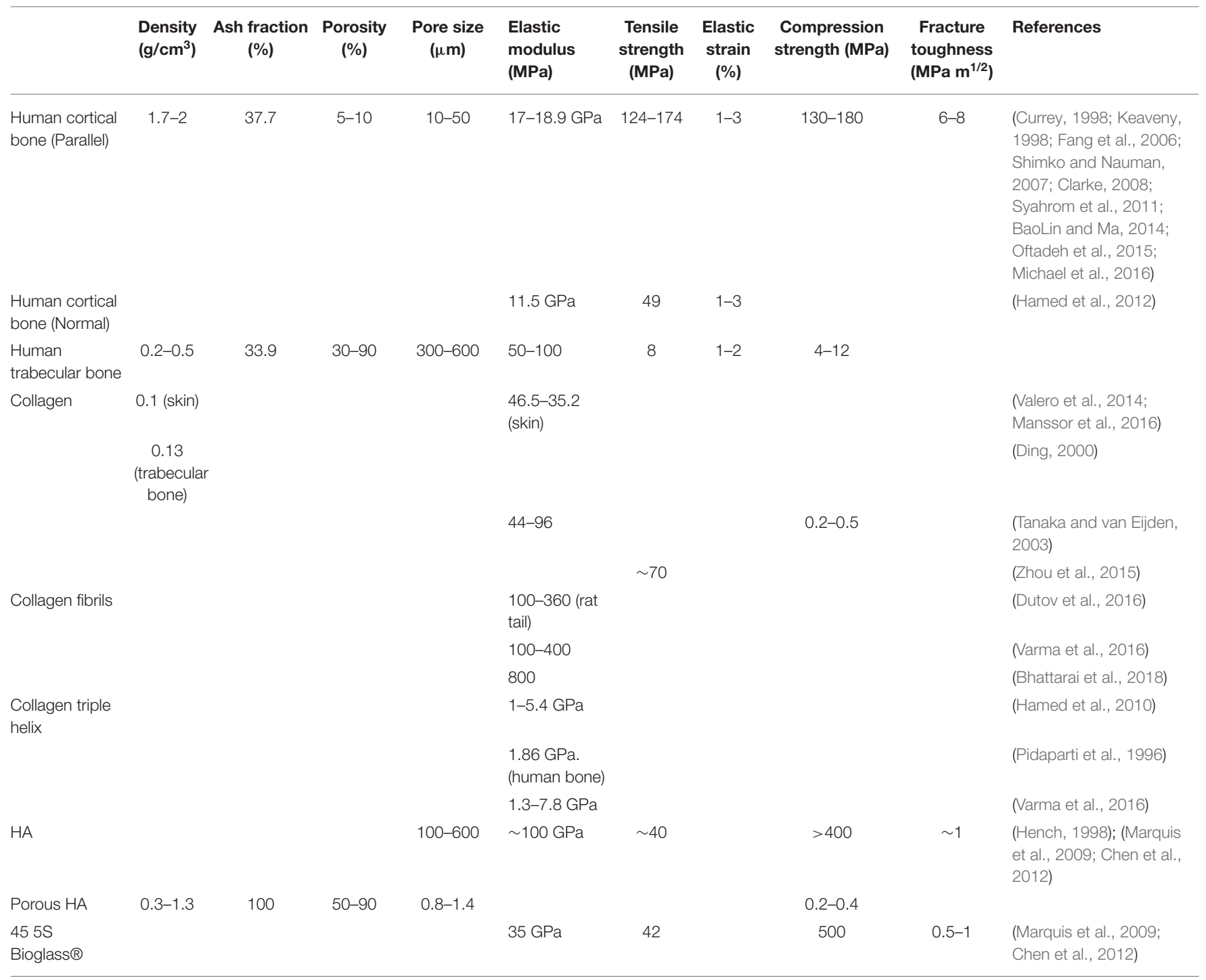

$\%$ mineral materials, 25 wt. \% organic materials, and 10 wt. \% water. The main inorganic mineral phase is represented by HA $\left(\mathrm{Ca}_{10}\left(\mathrm{PO}_{4}\right)_{6}(\mathrm{OH})_{2}\right)$. Apart from free ions (such as $\mathrm{CO}_{3}^{2-}, \mathrm{Na}^{+}$, $\mathrm{Mg}^{2+}$ ) and water, the remaining fraction is composed of organic components, type I collagen being the most abundant (nearly 90\%) and serving as anchoring support for HA crystals (Lafon et al., 2008; Ren et al., 2015; Arakawa et al., 2017; Lopes et al., 2018; Unal et al., 2018). On one hand, with a length of around 50$70 \mathrm{~nm}$ and width of $2-5 \mathrm{~nm}$, the HA crystals provide compression resistance. On the other hand, the collagen shaped in $50-500 \mathrm{~nm}$ diameter fibers provides bending resistance and strength during tension application (Venugopal et al., 2010; Gardin et al., 2012).

\section{Bone Cells}

Bone is constantly remodeled by cells with very specific functions, namely osteocytes, osteoclasts, osteoblasts, and bone lining cells (Figure 1). Bone remodeling occurs throughout life ensuring equilibrium between bone resorption and new bone formation
(Hadjidakis and Androulakis, 2006). In addition to correcting micro-damages, preventing the accumulation of old, more fragile bone and maintaining plasmatic calcium homeostasis, bone remodeling also adjusts its architecture to meet new mechanical needs and adapt to external stress. Differentiating from hematopoietic cells of the monocytic/macrophage lineage, the osteoclasts are multinucleated, giant cells. Their maturation and functions are intensely influenced by the stimulating activity of the osteocytic cells (Hadjidakis and Androulakis, 2006; Nakamichi et al., 2018). In the first remodeling phase (i.e., resorption), the osteoclasts digest the mineral and organic components of old bone. Resorption is followed by repopulation by mesenchymal cells. Finally, the resorbed bone is replaced by new tissue deposited by osteoblasts (Hadjidakis and Androulakis, 2006). In fact, secreting organic and inorganic components of bone ECM and other important functional proteins, osteoblasts are bone-building cells. Deriving from multipotent Mesenchymal Stromal Cells (MSCs), the osteoblasts synthesize type I 


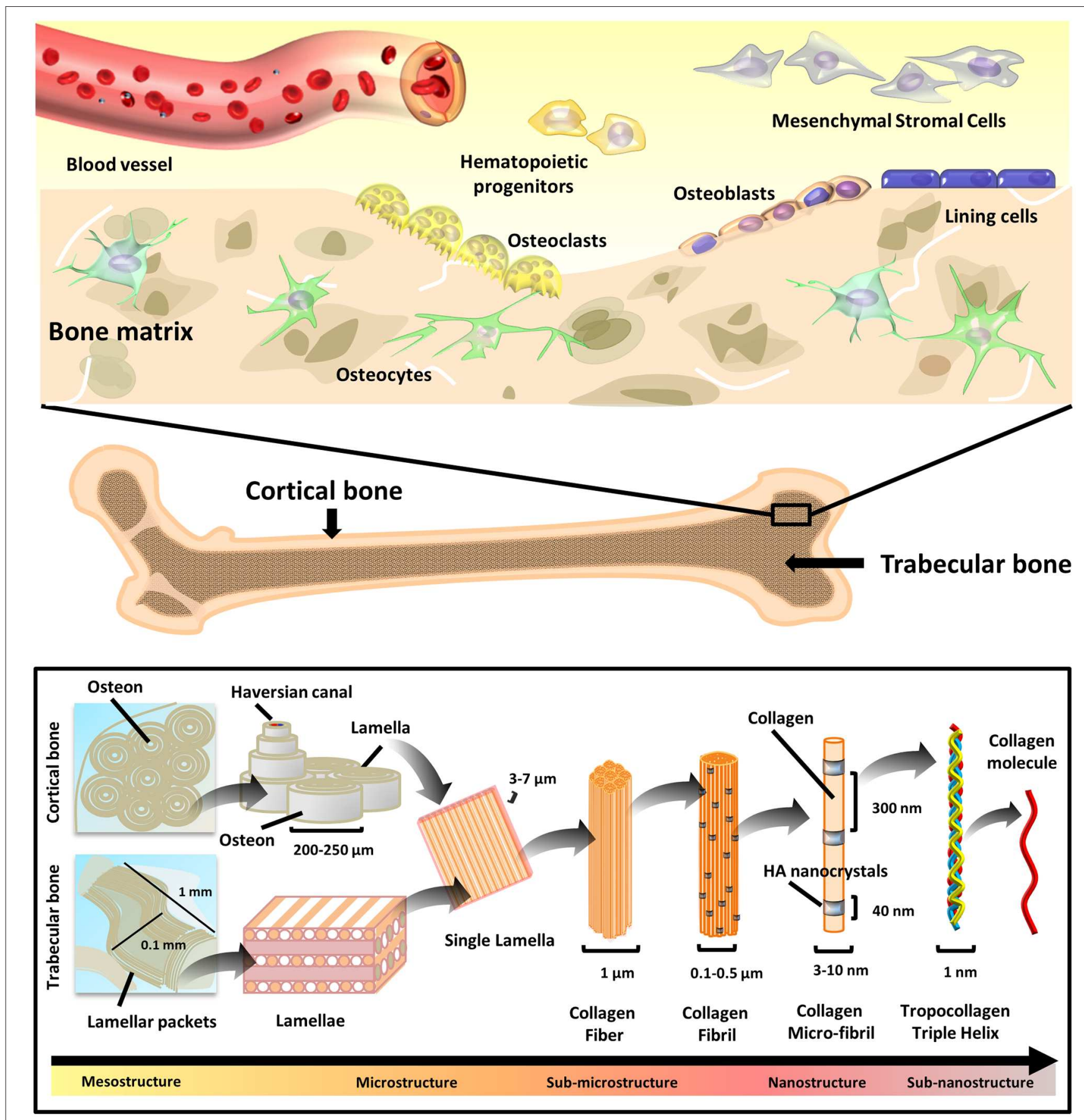

FIGURE 1 | Bone tissue composition and hierarchical morphology. Bone tissue composition: cell types present in the bone tissue (top), and hierarchical structure (bottom) of the cortical (compact) and trabecular (cancellous) bone. The various structural elements are represented, ranging from the mesostructures (i.e., osteons/lamellar packets) to the sub-nanostructures (i.e., collagen molecule).

collagen, glycoproteins, proteoglycans, $\gamma$-carboxylated proteins, bone sialoprotein (BSP), osteonectin, osteopontin (OPN), and osteocalcin (OCN). Beside several growth factors, including transforming growth factor $\beta$ (TGF- $\beta$ ), insulin like growth factor I and II (IGF-I and IGF-II), osteoblasts also produce bone morphogenic proteins (BMPs), and alkaline phosphatase (ALP)
(Mackie, 2003). The newly formed organic bone matrix, not yet calcified, is called an osteoid.

Being the most abundant cell type in bone, osteocytes are terminally differentiated osteoblasts with multifunctional roles, including: (i) orchestration of osteoblast and osteoclast activity, (ii) endocrine regulation of phosphate homeostasis, (iii) sensing 
of local mechanical strains, and (iv) cell signaling. Residing inside lacunae within the mineralized matrix, osteocytes connect to the vasculature and bone surface by sending dendritic projections through tiny tunnels called canaliculi (Tresguerres et al., 2020).

Finally, osteoblasts can also become quiescent cells laying on the bone surface, known as bone lining cells, which are responsible for directing the mineral uptake and release at the interface with other tissues (Streicher et al., 2017).

\section{Architecture}

Bone structure possesses a hierarchical organization (Figure 1). The overall pattern relies on the repetition of precise structural components at a nanoscale level, which then assemble into ordered micro-elements. The arrangement of micro-elements finally defines the bone macro-structure (Rho et al., 1998).

From a nanoscale point of view, bone is prominently composed of collagen fibers infiltered and surrounded by minerals. At this level, crystals and collagen fibrils are in the range of ten nanometers $(\mathrm{nm})$, which are made of sub-nanostructured crystals, collagens, and non-collagenous organic proteins. Subnano elements account for: HA plates in the size of $2 \times 25$ $\times 50 \mathrm{~nm}, 2-3 \mathrm{~nm}$ thick carbonate apatite and collagen molecules with diameter of 3-10 nm (Jasiuk, 2004). The most abundant collagen is the type I, whereas the predominant crystals are of calcium phosphate (mostly HA and $\beta$-Tricalcium Phosphate, $\beta$ TCP). The mineral deposition is regulated by non-collagenous organic proteins (namely OPN, BSP, osteonectin, and OCN) that, besides functioning as chelation-regulated reservoirs of calcium and phosphorous ions, also determine the orientation and size of mineral crystals.

Scaling up from the nano to the micro-structural frame, larger structures are present. The collagen fibrils assemble into larger fibers. Lamellae, namely planar sheets resulting from the association of mineralized collagen fibers, are 3-7 $\mu \mathrm{m}$ wide. Concentric layers of few (3-8) lamellae wrapped around a central canal produce cylindrical tubes with an overall diameter of about 200-250 $\mu \mathrm{m}$, termed as osteons or Haversian systems, running roughly parallel to the long axis of bone (Jasiuk, 2004). Size of the bone cells is also in the micro-domain, going from 1 to $2 \mu \mathrm{m}$ for bone lining cells to $50-100 \mu \mathrm{m}$ for mature osteoclasts (Manolagas, 2000).

Finally, the arrangement of these microstructures determines the histological nature of the bone macro-structure: the arrangement of lamellae into sinuous and irregular convolutions creates cancellous bone, namely a spongy tissue with high porosity degree, where trabeculae with typical millimeter dimensions ( $0.1 \mathrm{~mm}$ diameter and $1 \mathrm{~mm}$ length) are found. The regular microstructure arising from ordered cylindrical lamellae constructs impart high density to the tissue, generating the compact, cortical bone (Rho et al., 1998).

\section{DESIGN OF SCAFFOLDS FOR BONE TISSUE ENGINEERING}

Scaffolds are implemented in a damaged tissue niche and BTE principles are applied in order to trigger specific biological responses from the local environment, to induce the healing process (Figure 2). These principles consist in numerous strategies including gene therapy, drug and growth factor delivery, stem cell transplantation, and engineering of acellular scaffolds (Porter et al., 2009). The functions of BTE scaffolds consist in: (i) providing temporary mechanical support to the affected area and filling the void of bone defects, (ii) promoting the adherence and growth of circulating precursor cells and allowing for ECM deposition onto the scaffold surface (osteoconduction), (iii) eliciting vessels and bone in-growth into the porous scaffold, (iv) enhancing osteogenic differentiation via molecular signaling and new bone tissue formation (osteoinduction), (v) stimulating cell activity supporting the integration with native tissue (osteointegration), and (vi) delivering drugs or bioactive molecules to accelerate the healing process (Daculsi et al., 2013). To fulfill these functions, the scaffolds should ideally meet a number of important criteria. Besides being biocompatible, bioactive, osteoconductive, and osteoinductive, they should also maintain mechanical integrity throughout the healing process, whereas their degradation rate should guarantee the necessary mechanical support until the regeneration process is completed. Moreover, optimal cell penetration and ingrowth of vascularization into the implanted graft can occur if the structural interconnection of the internal architecture presents a pore diameter of at least $100 \mu \mathrm{m}$ (Wagoner Johnson and Herschler, 2011). The size and shape of pores should allow for the movements of cells and the diffusion of growth factors, nutrients, along with easy excretion of by-products from the cells. Interestingly, noticing that regenerative cells specifically react to the mechanical properties of the ECM (Discher et al., 2009), it has been demonstrated that the topography and rigidity of three-dimensional (3D) microenvironments can induce adult SCs, such as MSCs, to commit toward an osteogenic lineage (Discher et al., 2009). Being dependent on traction forces, the arrangement of the adhesion ligands and organization of integrin binding can be modulated by matrix stiffness, in turn triggering the osteogenic commitment (Huebsch et al., 2010). Accordingly, tuning the physical properties of adhesion substrates has become a trend in manufacturing transplantable grafts with optimized biological features and enhanced regenerative potential (Moosazadeh Moghaddam et al., 2019). However, the nature and extent of biophysical phenomena underlying the ECM-mediated cellular fate modulation still require a deeper comprehension. Furthermore, the scaffold surface chemistry should allow for functionalization with substances fostering the new osteoid matrix formation: therefore, the specific chemical groups for conjugation with bioactive factors should be numerous and accessible, permitting the application of simple coupling procedures based on either covalent or non-covalent interactions. The material features should also allow to implement strategies for smart, controlled and sustained release of the biomolecules (Liu and Ma, 2004; Wang et al., 2018; Cui et al., 2019). Hence, the selection of the polymer is a critical aspect for scaffold design.

\section{Polymer Scaffolds for BTE}

Polymers involved in TE are either of synthetic or natural origin (Figure 3) and diverse scaffold structures can be obtained from 


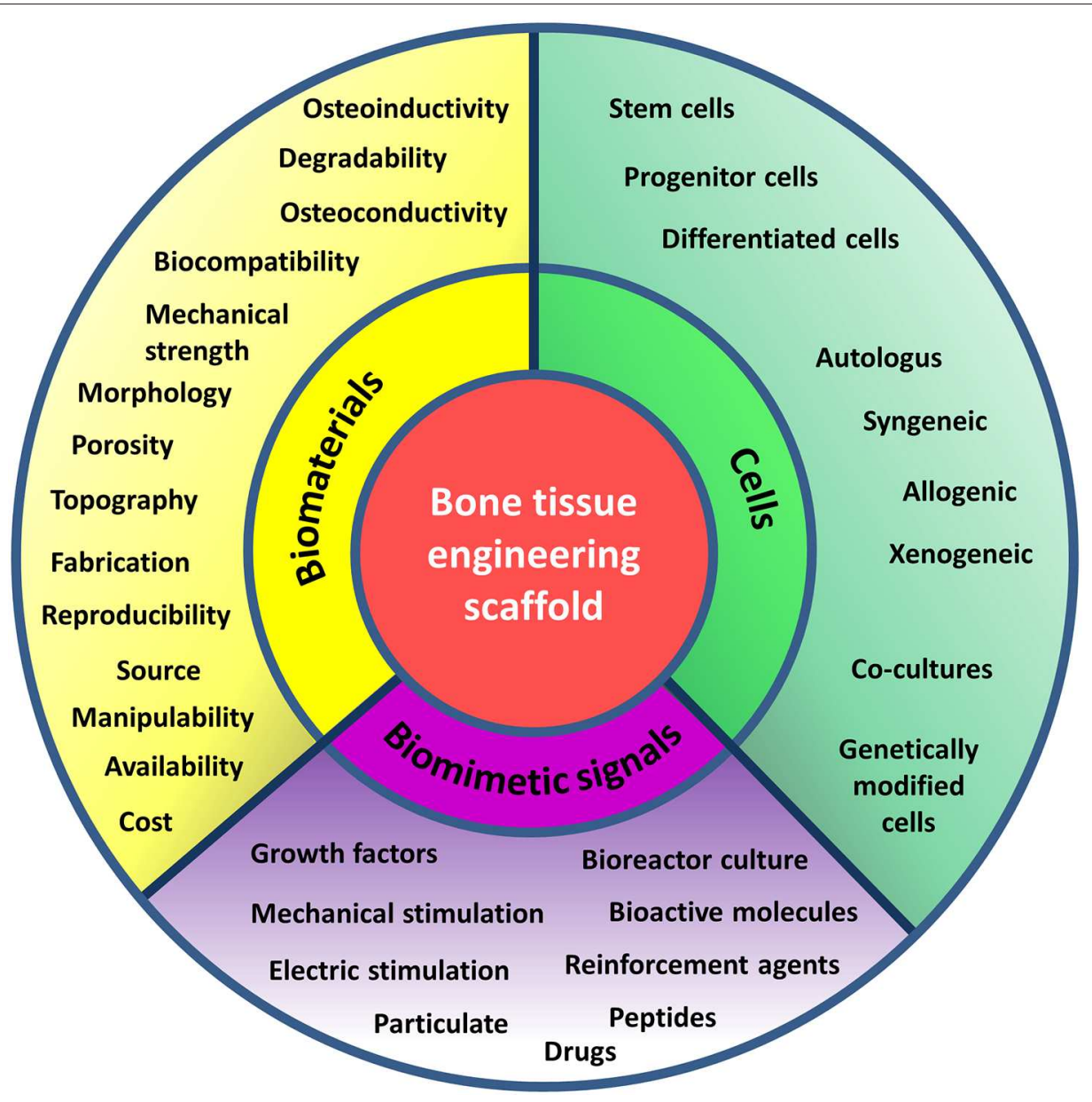

FIGURE 2 | Principles of bone tissue engineering. Principles of bone tissue engineering useful in the design of scaffolds serving as functional bone substitutes. TE combines cells, signaling molecules and biocompatible materials to design bioactive scaffolds and achieve successful reinstate of a variety of tissues. The criteria to be considered in the choice of the basal material to manufacture the matrix (yellow), the cell type (green), and the inductive signals (purple) to promote bone healing and formation are recalled by keywords in the respective sections of the diagram.

their processing (Liu and Ma, 2004; Bhattarai et al., 2018; Rao et al., 2018; Gentile et al., 2011) (Figure 4).

On one hand, synthetic polymers have been investigated for a variety of biomedical applications, especially due to the possibility to precisely tailor their properties during manufacturing (Nemati et al., 2019). Poly( $\alpha$-ester)s, polyurethanes, polyacetals, poly(ester amide)s, polyanhydrides, polyphosphazenes, and pseudo poly(amino acids), are the most eminent classes of synthetic polymers with utility in TE: for example, nanofibers of polyhydroxylketones (PHK), poly- $\varepsilon$-caprolactone (PCL), poly(methyl methacrylate) (PMMA), polyhydroxyl acids (PLA, PGA, PLGA), polyhydroxybutyrates (PHB), polyvinyl alcohol (PVA), polyethylene terephthalate (PET), and polyhydroxybutyrate-co-hydroxyvalerate (PHVB) can form porous, interwoven, rigid scaffolds supporting enhanced cell growth as compared to their flat films counterparts (Li et al., 2014). On the other hand, as products of the metabolic activity or other physiological processes of living organisms, the natural polymers display high biocompatibility and similarity to the natural ECM including numerous cell recognition and adhesion sites (Bonani et al., 2018; Rao et al., 2018). However, the specific source and extraction process can deeply affect their characteristics and the resulting biological activity. Because of their variability, the standardization of manufacturing procedures is critical for successful use of natural polymers in TE (Bhattarai et al., 2018; Bonani et al., 2018). Even though natural polymers can be considered as the first biodegradable biomaterials employed clinically (Nair and Laurencin, 2007), various commercially available synthetic polymers are endowed with mechanical and physicochemical features comparable to those of biological tissues (Gunatillake et al., 2006). Advantages and disadvantages associated with the biomedical use of natural or synthetic polymers are listed in Table 2 (BaoLin and Ma, 2014; Mohamed and Shamaz, 2015; Bhatia, 2016; Salehi-Nik et al., 2017).

Porous 3D scaffolds for BTE can be fabricated by processing the polymers through different technologies (Figure 4). The traditional ones include: solvent casting and particulate leaching, 


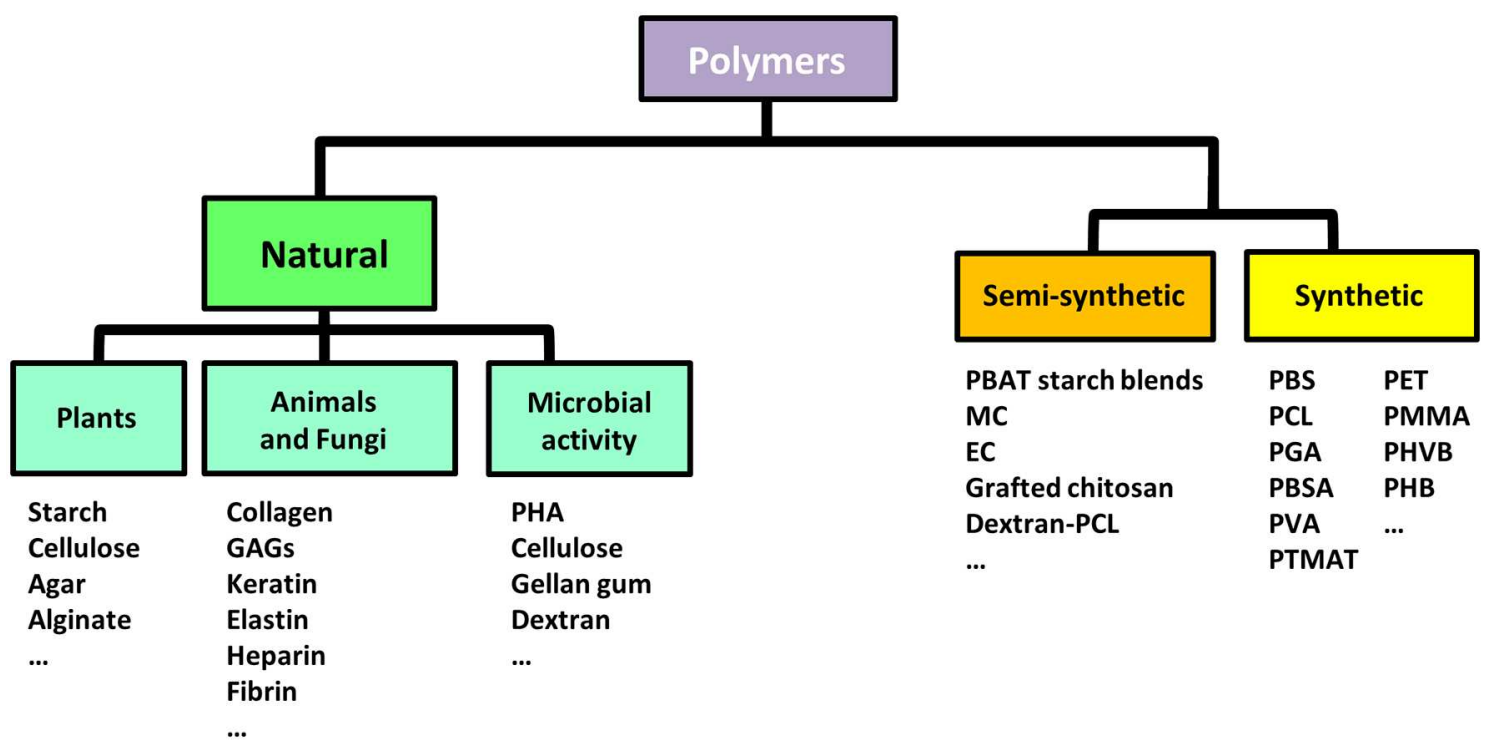

FIGURE 3 | Biodegradable polymers for biomedical applications. Classification of biodegradable polymers commonly used in biomedical applications based on the origin of their source (natural, synthetic, or semi-synthetic). GAGs, Glycosaminoglycans; PHA, Poly(hydroxyalkanoates); PBAT, Poly(butylene

adipate-co-terephthalate); MC, Methyl-cellulose; EC, Ethyl-cellulose; PBS, Poly(butylene succinate); PLA, Poly(lactic acid); PVA, Poly(vinyl alcohol); PGA, Poly(glycolic acid); PBSA, Poly(butylene succinate-co-adipate); PHK, Poly(hydroxylketones); PCL, Poly-e-caprolactone; PMMA, Poly(methyl methacrylate); PHB,

Poly(hydroxybutyrates); PET, Poly(ethylene terephthalate); PHVB, Poly(hydroxybutyrate-co-hydroxyvalerate); PTMAT, Poly(methylene adipate/terephthalate).

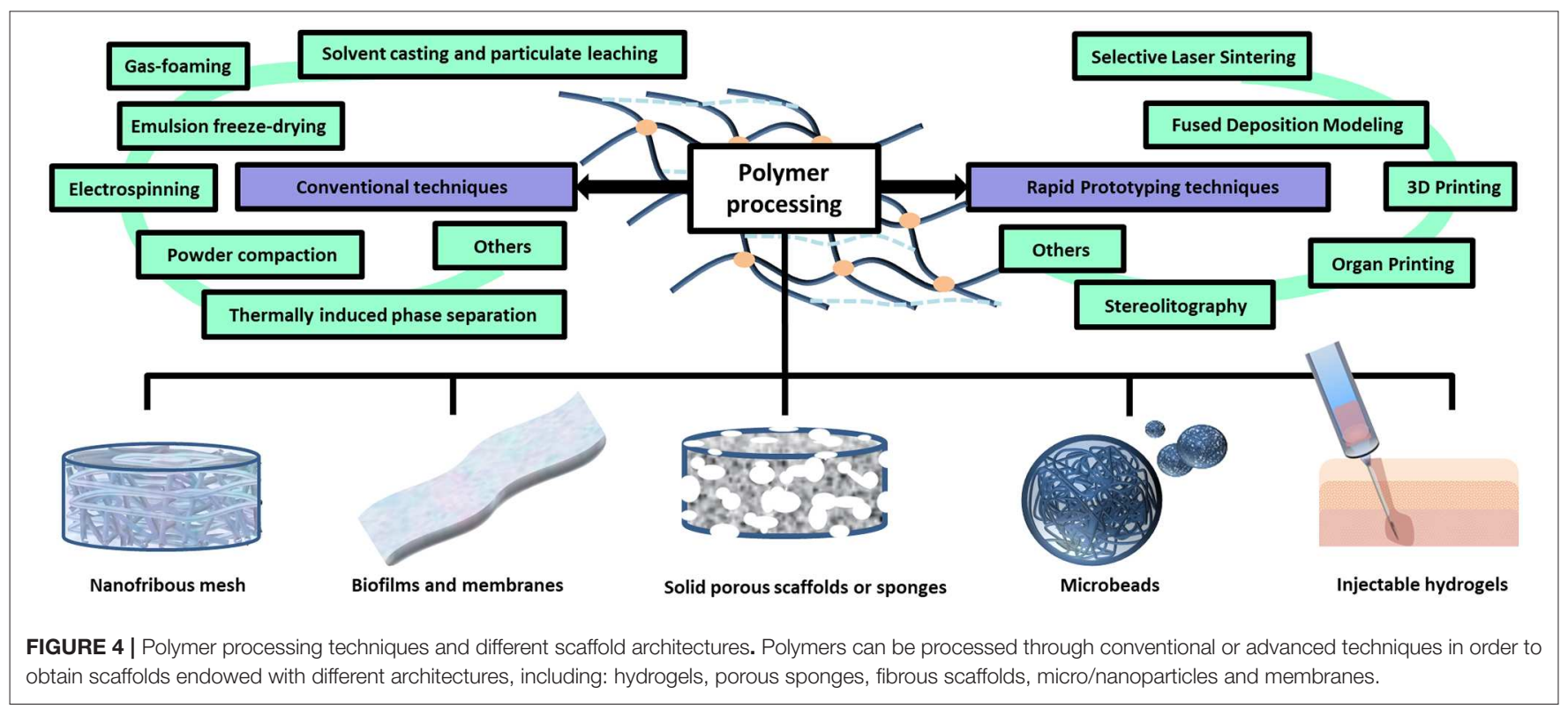

gas foaming, emulsion freeze-drying, electrospinning, and thermally induced phase separation (Liu and Ma, 2004). The "solvent casting and particulate leaching" method simply requires to add certain water soluble salt particles (e.g., sodium chloride, sodium citrate) into a solution of biodegradable polymers, which is then casted into a mold of the defined shape. After removing the solvent by evaporation or lyophilisation, pores are formed by leaching out the salt particles (Ma and Langer, 1998). In gas foaming, a gas (usually carbon dioxide) is applied at elevated pressure to solid polymer disks until reaching saturation. Then, the sudden release of the gas causes thermodynamic instability of the polymer system, enabling several gas bubbles to nucleate and grow inside the material, which eventually define a spongy structure (Harris et al., 1998). In emulsion freeze-drying, a polymer solution in organic solvent and water are homogenized and rapidly cooled down to preserve the liquid state structure. Solvent and water are eliminated by freeze-drying, leaving a structure with high porosity degree (even greater than 90\%) 
TABLE 2 | Advantages and disadvantages of natural and synthetic polymers used in scaffold fabrication for tissue engineering.

\begin{tabular}{|c|c|c|c|}
\hline & ADVANTAGES & DISADVANTAGES & References \\
\hline Synthetic polymers & $\begin{array}{l}\text { - Defined purity and reproducible } \\
\text { chemical/mechanical properties } \\
\text { - Appropriate mechanical properties } \\
\text { - Low immune response } \\
\text { - Low production costs } \\
\text { - Off-the-shelf availability and production in large } \\
\text { uniform quantities } \\
\text { - Opportunity to tailor material properties } \\
\text { during manufacturing }\end{array}$ & $\begin{array}{l}\text { - Poor biocompatibility } \\
\text { - Risk of biodegradation side effects (nanotoxicity, } \\
\text { inflammation, etc.) } \\
\text { - Difficult 3D printing } \\
\text { - Questionable cell-matrix interaction } \\
\text { - Loss of mechanical strength after degradation } \\
\text { (biodegradable polymers) } \\
\text { - Low ductility } \\
\text { - Effects of long-term permanence in the body } \\
\text { (non-degradable polymers) } \\
\text { - Uncontrollable shrinkage effects }\end{array}$ & $\begin{array}{l}\text { (Gunatillake et al., 2006; BaoLin } \\
\text { and Ma, 2014; Bhatia, 2016) }\end{array}$ \\
\hline Natural polymers & $\begin{array}{l}\text { - Natural origin } \\
\text { - Biocompatibility } \\
\text { - Presence of cell recognition and adhesion sites } \\
\text { - Similarity with native ECM } \\
\text { - Biodegradability } \\
\text { - Not require harsh chemicals for processing } \\
\text { - Bioresorbability } \\
\text { - Bioactivity }\end{array}$ & $\begin{array}{l}\text { - Properties dependence on extraction and } \\
\text { processing procedures } \\
\text { - Inadequate mechanical properties } \\
\text { - Expensive productive methods } \\
\text { - Susceptibility to cross-contamination } \\
\text { - Difficult processing } \\
\text { - Low stability }\end{array}$ & $\begin{array}{l}\text { (Bhatia, 2016; Salehi-Nik et al., } \\
\text { 2017) }\end{array}$ \\
\hline
\end{tabular}

(Whang et al., 1995). Electrospinning is a technique where high electrostatic forces are used to squeeze a viscoelastic solution into jet, overcoming its internal cohesive forces: upon solvent evaporation, nano/micro sized fibers are formed (Bürck et al., 2018). In sol-gel technique, inorganic metal salts or metal organic compounds are dissolved in a solvent in order to allow a colloidal suspension (namely a sol) to form as a consequence of a series of hydrolysis and polymerization reactions. After being casted in a mold, the sol turns into a wet gel which is then subjected to heat treatment to produce dense glass or ceramic articles (Xing et al., 2010). Initially used for the preparation of porous membranes and then $3 \mathrm{D}$ scaffolds, the controlled thermally induced phase separation technique accounts for a first processing step where the polymers are dissolved into solvent at high temperature. Afterwards, lowering the temperature induces a solid-liquid or liquid-liquid phase separation. Finally, the solidified solventrich phase is removed via sublimation, leaving hollow spaces determining the matrix porosity (Zhang and Ma, 2002). Other traditional fabrication techniques include: fiber mesh, fiber bonding, melt molding, and powder compaction methods (Garg et al., 2012). More advanced procedures are based on a rapid prototyping approach (also known as solid free form fabrication), such as in 3D printing, where specific objects or components are produced by ink-jet printing a binder onto sequential powder layers (Yang et al., 2002). Other systems that fall under the rapid prototyping category are: stereolitography, selective laser sintering, fused deposition modeling, organ printing, and membrane lamination, which have been reviewed somewhere else (Garg et al., 2012).

Depending on the final use of the scaffolds, different mechanical behaviors might be required such that the choice of polymers should be adapted also accordingly. For instance, due to the difficulty of reaching the target areas, injectable and soft materials are preferred in dentistry, where stents have to fit the small deposition sites in the pulpo-dentinal complex and periodontal apparatus (Chieruzzi et al., 2016). In this context, polymers with gelation ability are suitable. The surgical reconstruction of bone and cartilage instead requires larger grafts simulating the precise mechanical properties of hard tissues: this effect can be obtained through a well-balanced composition of bone-bioactive inorganic substances (like HA, bioactive glasses, and calcium phosphate) and polymers. Especially, the natural ones (such as collagen, chitosan, and silk fibroin) are preferred to generate soft matrices with great potential in BTE, thanks to a high biodegradability, cytocompatibility and a minimal immunogenicity (Bhattarai et al., 2018; Rao et al., 2018). Furthermore, besides being the main structural component in scaffolds, another relevant function of BTE polymers consists in delivering bioactive molecules and drugs (Zamani et al., 2010). In biodegradable polymers, the kinetics of degradation occurring under physiological conditions depends on the nature of polymer blends (copolymer or pristine), architectural scale (micro or nano-scale), and presence of reaction accelerators or inhibitors (La Mantia et al., 2017). Beyond that, various mechanisms for controlled release of biofactors can be implemented: for instance, the instability of the drug-matrix linkage can derive from hydrolysis or enzymatic digestion, resulting into tunable biodegradation rate (Nair and Laurencin, 2007).

\section{Natural Polymers in BTE}

Natural polymers can be either protein or polysaccharide-based (Garg et al., 2012). Unlike polysaccharides, proteins present the amino acid sequences typically associated with cell attachment via integrin-binding domains. Therefore, cell adhesion and osteoconductivity have to be enhanced in polysaccharidic scaffolds by chemical surface modifications (Luna et al., 2011), mixing with osteoconductive materials, and incorporation of integrin-binding sequences or cell adhesion proteins (Kowalczewski and Saul, 2018). The most commonly studied polymers of natural origin for BTE are collagen/gelatin, alginate, 
chitosan, silk, hyaluronic acid, elastin, glycosaminoglycans (GAGs), peptides, and others (Vagaská et al., 2010; Jahan and Tabrizian, 2016). Concentration, conditions of polymerization and the introduction of functional groups allow for a modulation of the porosity, charge, and mechanical strength of natural polymers, as well as the addition of chemicals, proteins, peptides, and cells enables to control their bioactivity (Lee and Shin, 2007; Lee and Yuk, 2007). In the following paragraphs, the properties and use of polymers will be discussed, highlighting recent studies where these materials have been modified in different manners in order to improve their osteogenic capabilities. Although various polymeric materials have been already investigated, no single biodegradable polymer can meet all the requirements for application in BTE: the advantages and disadvantages of the most widely used polymers are summarized in Table 3.

\section{Collagen \\ Structure and characteristics}

The collagens are animal-derived fibrous glycoproteins. In vertebrates, they account for 28 distinct types coded by at least 45 different genes (Meyer, 2019). As a major constituent of the ECM in various connective tissues, collagens are the most abundant protein in the human body ( 25 to $35 \%$ of the whole-body protein content), and as a primary component in bone, they are also ideal candidates for $3 \mathrm{D}$ scaffold design (Aravamudhan et al., 2013; Dong and Lv, 2016). In tendon, bone, skin, and cartilage, a restricted number of collagen types dominate: while cartilage mainly consists of type II collagen, collagen type I is prevalent in skin, tendon and bone (beside the less frequent types III and V). The collagen molecule structurally consists of a triple helix of elongated fibrils, known as a collagen helix. The helix can contain the same or very similar polypeptide chains leading to homo- or hetero-trimers (Gross et al., 1955; Bürck et al., 2018). In natural bone, collagen fibrils serve as a template for mineralization. Biocompatible, bioactive, and rich in surface-binding sites for cells, collagen stimulates cell adhesion, proliferation, and differentiation, representing therefore an excellent substrate for scaffold fabrication.

\section{Manufacturing and properties of collagen scaffolds}

Collagen can be shaped into nanofibers via electrospinning (Matthews et al., 2002; Bürck et al., 2018). Different solvents, such as hexafluoroisopropanol (HFIP), mixture of formic and acetic acid, and diluted acetic acid, have been used to electrospin collagen for nanofibrous scaffold preparation (Ekaputra et al., 2011; Dippold et al., 2017; Dulnik et al., 2018). To form BTE scaffolds, collagen can also be used in the form of hydrogel. The polymerization conditions, such as $\mathrm{pH}$, collagen type and concentration, affect the microstructure of the resulting matrices, acting on the fibril diameter and density (Roeder et al., 2002). Also, the hydraulic permeability of collagenous scaffolds can be manipulated to optimize not only the internal oxygen flow and nutrient exchange, but also the overall mechanical properties of the construct and the cell-scaffold interactions. Depending on pore size, number, orientation, distribution and interconnectivity, the ability of collagen hydrogels to transfer fluids through their interstices varies under applied pressure. Moreover, the collagen fibril density and the hydraulic permeability of the gel inversely correlate: it was demonstrated that in gels with higher fibril densities and low hydraulic permeability, the application of a plastic static compression greatly increases their modulus and reduces the MSC-induced gel contraction (Serpooshan et al., 2010). Moreover, even though the influence of hydraulic permeability on the osteoconduction and osteoinduction remains to be fully defined, evidences of improved MSC proliferation, differentiation, and mineralization were found in compressed collagens, appearing therefore promising for bone grafting purposes. In another study, scaffolds composed of type 1 and 3 collagen hydrogels in the ratio 9:1 were seeded with MSCs from different sources to assess their ability to undergo osteogenic differentiation (Schneider et al., 2010). On this model, the cells were able to migrate, colonize and remodel the matrix through the secretion of matrix metalloproteinases (MMP), inducing its strengthening and contraction. As compared to other polymers (like alginate), collagen hydrogels showed increased binding ability for co-cultures of MSCs and endothelial cells (ECs) useful in studying pre-vascularization of engineered bone (Nguyen et al., 2017). These systems, in which an amplified gene and protein expression of osteogenic and angiogenic markers was demonstrated, further increased by bioreactor-induced shear stress, are expected to advance the design of microenvironments for bone tissue substitutes.

Nevertheless, pure collagen scaffolds are fragile, such that direct cell culture causes extensive gel contraction and unstable geometrical properties (Mizuno et al., 2000; Otsuka et al., 2013). Additionally, they owe insufficient bioactivity to foster the cell bone forming ability and poor mechanical strength to sustain bone regeneration, often making it necessary to add polymers and other biomolecules in order to improve osteoinductivity (Harley et al., 2007). For instance, the low Young modulus value of collagen (see Table 1) can be increased by crosslinking with synthetic polymers (Bhattarai et al., 2018). In another study, to compensate poor mechanical properties, a collagen hydrogel was inserted onto a macro-channeled PCL scaffold fabricated via robotic dispensing technique (Yu et al., 2012). The growth and osteogenesis by MSCs were studied in a perfusion bioreactor, demonstrating upregulation of genes involved in mechanotransduction, the process by which physical forces are converted into biochemical signals that are essential for bone formation (Rosa et al., 2015).

\section{Biocomposites}

A variety of bioactive compounds, including bioceramics, carbon, and polymer materials, have been incorporated into collagen to prepare composite scaffolds in which porosity, structural stability, osteoinductivity, and osteogenicity are improved (Zhang et al., 2017). Calcium phosphate (CaP) and calcium silicate $(\mathrm{CaSi})$ bioceramics are combined with collagen to simulate the intrinsic inorganic compartment of bone. Based on direct mixing and co-precipitation principles respectively, the suspension and immersion techniques are the main manufacturing methods to integrate bioceramics into collagen (Kikuchi et al., 2004; Yunoki et al., 2007; Xia et al., 2016). 
TABLE 3 | Advantages and disadvantages of various natural polymers used in fabrication of BTE scaffolds.

\begin{tabular}{|c|c|c|c|}
\hline & ADVANTAGES & DISADVANTAGES & References \\
\hline \multicolumn{4}{|c|}{ Protein-based polymers } \\
\hline Collagen & $\begin{array}{l}\text { - Biocompatible } \\
\text { - Biodegradable } \\
\text { - Fibrous morphology } \\
\text { - Non-toxic } \\
\text { - Non-antigenic } \\
\text { - Mimic native bone ECM topography } \\
\text { - Biologically renewable } \\
\text { - Bioadhesive } \\
\text { - Biofunctional } \\
\text { - Ability to be cross-linked }\end{array}$ & $\begin{array}{l}\text { - Poor mechanical properties } \\
\text { - Low stability } \\
\text { - Fusion of nanofibers in aqueous environment } \\
\text { - Low melting point } \\
\text { - Viral and prion contamination } \\
\text { - Difficult processing } \\
\text { - Difficult control over extent and rate of degradability } \\
\text { - Potentially damaged by sterilization methods } \\
\text { - Expensive if produced by recombinant technologies }\end{array}$ & $\begin{array}{l}\text { (Whang et al., 1999; Dong and } \\
\text { Lv, 2016; Zhang et al., 2017) }\end{array}$ \\
\hline Gelatin & $\begin{array}{l}\text { - Biocompatible } \\
\text { - Biodegradable } \\
\text { - Anti-thrombogenic } \\
\text { - Good cell recognition properties } \\
\text { - Low antigenicity } \\
\text { - Easy to mold into a range of shapes (injectable hydrogels } \\
\text { and sponges) }\end{array}$ & $\begin{array}{l}\text { - Low stability } \\
\text { - Chemical cross-linking needed } \\
\text { - Poor mechanical properties } \\
\text { - Brittleness }\end{array}$ & $\begin{array}{l}\text { (Garg et al., 2012; Echave et al., } \\
\text { 2017) }\end{array}$ \\
\hline Silk fibroin & $\begin{array}{l}\text { - Biocompatible } \\
\text { - Biodegradable } \\
\text { - Slow degradation } \\
\text { - Excellent mechanical properties } \\
\text { - High thermal stability } \\
\text { - High mechanical strength }\end{array}$ & $\begin{array}{l}\text { - Reduced availability (e.g. low production from spiders) } \\
\text { - High brittleness } \\
\text { - Residue contaminants }\end{array}$ & $\begin{array}{l}\text { (Shi et al., 2016; Kowalczewski } \\
\text { and Saul, 2018) }\end{array}$ \\
\hline $\begin{array}{l}\text { Hyaluronic } \\
\text { acid }\end{array}$ & $\begin{array}{l}\text { - Highly biocompatible } \\
\text { - Biodegradable } \\
\text { - Excellent viscoelasticity } \\
\text { - Excellent water solubility } \\
\text { - Natural component of ECM and structurally similar to GAGs } \\
\text { - Easy and controllable production in a large scale via } \\
\text { microbial fermentation } \\
\text { - Easy functionalization } \\
\text { - Negatively charged } \\
\text { - Easy manipulation }\end{array}$ & $\begin{array}{l}\text { - Difficult processing by electrospinning (due to high } \\
\text { viscosity and surface tension) } \\
\text { - Poor mechanical properties } \\
\text { - Expense of preservation and storage in a cryo-freezer. }\end{array}$ & $\begin{array}{l}\text { (Khan and Ahmad, 2013; Bae } \\
\text { et al., 2014; Shi et al., 2016) }\end{array}$ \\
\hline Fibrin & $\begin{array}{l}\text { - Biocompatible } \\
\text { - Biodegradable } \\
\text { - Insoluble into water } \\
\text { - Improved cellular interaction }\end{array}$ & $\begin{array}{l}\text { - Low integrity and rapid degradation in vivo } \\
\text { - Instability } \\
\text { - Low mechanical stiffness }\end{array}$ & $\begin{array}{l}\text { (Garg et al., 2012; Noori et al., } \\
\text { 2017) }\end{array}$ \\
\hline $\begin{array}{l}\text { Chondroitin } \\
\text { sulfate }\end{array}$ & $\begin{array}{l}\text { - Non-toxic degradation products (oligosaccharides) } \\
\text { - Non-immunogenic }\end{array}$ & - Readily water-soluble nature & $\begin{array}{l}\text { (Garg et al., 2012; Farrugia et al., } \\
\text { 2018) }\end{array}$ \\
\hline Spongin & $\begin{array}{l}\text { - Biocompatible } \\
\text { - Inexpensive } \\
\text { - Low risk of transmission of infection-causing agents } \\
\text { - Widely available } \\
\text { - Well-established farming techniques } \\
\text { - Appropriate porosity and surface chemistry } \\
\text { - Stable in vitro }\end{array}$ & $\begin{array}{l}\text { - Need for determining aquaculture systems or farming } \\
\text { (when ex situ cultivation is difficult) } \\
\text { - Species-dependent variability of characteristics } \\
\text { and composition }\end{array}$ & $\begin{array}{l}\text { (Green et al., 2003; Granito } \\
\text { et al., 2016) }\end{array}$ \\
\hline Heparin & - Preserve the growth factor stability and bioactivity & - Reduced cell growth rate & (Chung and Park, 2007) \\
\hline \multicolumn{4}{|c|}{ Polysaccharide-based polymers } \\
\hline Chitosan & $\begin{array}{l}\text { - Biocompatible } \\
\text { - Biodegradable } \\
\text { - Biologically renewable } \\
\text { - Non-toxic } \\
\text { - Non-antigenic } \\
\text { - Inexpensive } \\
\text { - Positively charged } \\
\text { - Antibacterial properties }\end{array}$ & $\begin{array}{l}\text { - Difficult processing by electrospinning } \\
\text { - Immunogenicity } \\
\text { - Long delay in bone formation (after several months or } \\
\text { years) } \\
\text { - Relatively weak mechanical strength and stability }\end{array}$ & $\begin{array}{l}\text { (Garg et al., 2012; Levengood } \\
\text { and Zhang, 2014; Shi et al., } \\
\text { 2016) }\end{array}$ \\
\hline
\end{tabular}


TABLE 3 | Continued

\begin{tabular}{|c|c|c|c|}
\hline & ADVANTAGES & DISADVANTAGES & References \\
\hline Alginate & $\begin{array}{l}\text { - Biocompatible } \\
\text { - Biodegradable } \\
\text { - Simple gelation methods } \\
\text { - Crossilinkable and injectable } \\
\text { - Easy functionalization } \\
\text { - Resistance to acidic conditions } \\
\text { - Negatively charged } \\
\text { - Adjustable properties based on the two monomer content }\end{array}$ & $\begin{array}{l}\text { - Poor mechanical properties } \\
\text { - Leaching of entrapped drugs } \\
\text { - Uncontrolled degradation kinetics } \\
\text { - Difficult sterilization and handling }\end{array}$ & $\begin{array}{l}\text { (Shi et al., 2016; Kowalczewski } \\
\text { and Saul, 2018) }\end{array}$ \\
\hline Starch & $\begin{array}{l}\text { - Biodegradable } \\
\text { - Abundant } \\
\text { - Overwhelming } \\
\text { - Biological renewability }\end{array}$ & $\begin{array}{l}\text { - Brittleness } \\
\text { - Highly difficult processing } \\
\text { - Destruction or reorganization of the structure of the } \\
\text { semi-crystalline native starch granules }\end{array}$ & $\begin{array}{l}\text { (Martins et al., 2009; Khan and } \\
\text { Ahmad, 2013) }\end{array}$ \\
\hline Agar & $\begin{array}{l}\text { - Biocompatible } \\
\text { - Biodegradable }\end{array}$ & $\begin{array}{l}\text { - Difficult processing } \\
\text { - Difficult extraction }\end{array}$ & $\begin{array}{l}\text { (Garg et al., 2012; Witzler et al., } \\
\text { 2019) }\end{array}$ \\
\hline Dextran & $\begin{array}{l}\text { - Biocompatible } \\
\text { - Biodegradable } \\
\text { - Several derivatives with different molecular weights are } \\
\text { readily available }\end{array}$ & $\begin{array}{l}\text { - Risks of coagulation abnormalities } \\
\text { - Cost } \\
\text { - Over hydration } \\
\text { - Risk of anaphylaxis }\end{array}$ & $\begin{array}{l}\text { (Garg et al., 2012; Nikpour et al., } \\
\text { 2018) }\end{array}$ \\
\hline Cellulose & $\begin{array}{l}\text { - Biocompatible } \\
\text { - Inexpensive } \\
\text { - Readily available } \\
\text { - Easily converted into derivatives } \\
\text { - Porous }\end{array}$ & $\begin{array}{l}\text { - Long renewal time } \\
\text { - Low degradability in vivo }\end{array}$ & $\begin{array}{l}\text { (Khan and Ahmad, 2013; Sofi } \\
\text { et al., 2018) }\end{array}$ \\
\hline Carrageenans & $\begin{array}{l}\text { Is High molecular flexibility } \\
\text { - Thixotropic nature }\end{array}$ & $\begin{array}{l}\text { - Gel dissolution in the absence of a gel-inducing } \\
\text { reagent } \\
\text { - Elevated melting temperature }\end{array}$ & $\begin{array}{l}\text { (Garg et al., 2012; Yegappan } \\
\text { et al., 2019) }\end{array}$ \\
\hline Gellan gum & $\begin{array}{l}\text { - Resistance to acidic conditions and high temperature } \\
\text { - Transparency, flexibility and elasticity in the highly acylic gels }\end{array}$ & $\begin{array}{l}\text { - Low elasticity and brittleness when used in the low } \\
\text { acyl form }\end{array}$ & $\begin{array}{l}\text { (Pereira et al., 2013; Manda } \\
\text { et al., 2018) }\end{array}$ \\
\hline
\end{tabular}

Some examples of collagen biocomposites and related properties are reported in Table 4.

It is well-established that adding HA not only increases the compression modulus of collagen scaffolds, but also provides a larger and rougher adherence surface allowing for improved adhesion, bioactivity, and proliferation of cells (Sionkowska and Kozlowska, 2013). Collagen scaffolds enriched with HA modified by chemical substitutions with $\mathrm{Mg}^{2+}$ can exert a regulatory effect on bone formation process (Kikuchi et al., 2001; Calabrese et al., 2016), while Zn-based substitution stimulates the expression of osteogenesis-related genes and cell proliferation (Minardi et al., 2015). After years of exploration, collagen-HA composites with controllable micropore organization and interconnectivity, isotropic equiaxed structures and tunable properties can be manufactured (Xia et al., 2013), paving the way to a systematic production of tailored substitutes fitting the bone defect shapes thanks to the development of the 3D printing technology. $\beta$-TCP has also been widely employed to prepare collagen composites for bone regeneration (Arahira and Todo, 2016). With respect to HA, $\beta$-TCP displays lower $\mathrm{Ca} / \mathrm{P}$ ratio $(\approx 1.67$ and 1.5 , respectively $)$ and faster degradation rate, leading to complete replacement in newly formed bone tissues (Cao and Kuboyama, 2010). Five to 10 wt. \% has been recommended as an optimal $\beta$-TCP dose to achieve appropriate mechanical stiffness and release of $\mathrm{Ca}^{2+}$ ions in collagen scaffolds, eventually supporting cell proliferation, neovascularization and bone formation in vivo
(Murakami et al., 2017). Cerasorb $®$ Ortho Foam, a type of collagen- $\beta$-TCP composite, was used to fill bone defects of critical size in a rabbit distal femoral condyle model, stimulating bone healing, and causing neither toxic nor immunological reactions (Zheng et al., 2014). In this study, the swelling of collagen was also found to support a better contact of the implant with the surrounding tissue.

Among silica-based osteoconductive and osteoinductive glass biomaterials, bioactive glasses (BGs) are structurally based on $\mathrm{SiO}_{2}-\mathrm{CaO}-\mathrm{P}_{2} \mathrm{O}_{5}$ networks. Besides promoting both osteogenesis and angiogenesis in vitro and in vivo (Xynos et al., 2001; Gorustovich et al., 2010), addition of BGs generates collagen composites with high-performance in mimicking bone mineralization, given that the release of $\mathrm{Ca}, \mathrm{P}$, and $\mathrm{Si}$ causes $\mathrm{Ca}$ and $\mathrm{P}$ precipitation at the surface of the implants with consequent deposition of amorphous Ca-P crystals. The crystals finally transform into hydroxycarbonate apatite (HCA) by dehydration (Izquierdo-barba et al., 2008). Similarly, the wollastonite $\left(\mathrm{CaSiO}_{3}\right)$ releases $\mathrm{Si}$ and $\mathrm{Ca}$ ions stimulating osteogenic differentiation and cell proliferation, and inducing the deposition of bone-like apatite on their surface after soaking in simulated body fluids (SBF) ( $\mathrm{Li}$ and Chang, 2005, 2013; Wang X. et al., 2015). But even though wollastonite enhances mechanical strength of the constructs, bone regeneration ability and angiogenesis, more investigations are needed to define the bioactivity, osteogenic 
TABLE 4 | Physical properties of BTE scaffolds based on biocomposites with natural polymers.

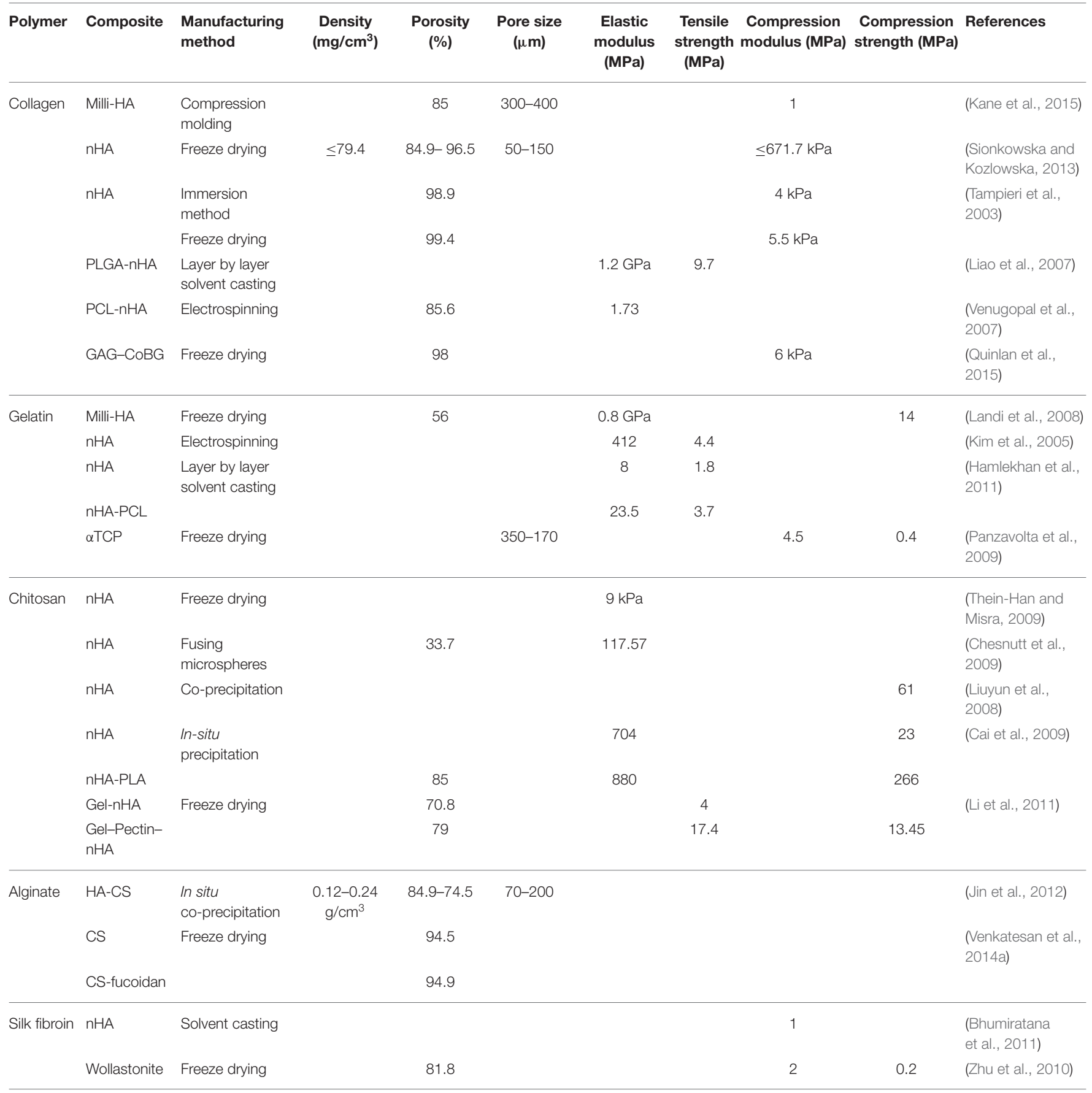

potential, and immunogenicity of collagen composites upon in vivo implantation.

To improve osteoinduction, osteointegration, structural stability, and mechanical properties, other materials can be combined to collagen. For instance, carbon nanotubes (CNTs) are reported to augment the tensile strength, the stress resistance and the apatite deposition ability in collagen composites, as well as to the enhance osteogenic differentiation of MSCs (Usui et al., 2008; Da Silva et al., 2009; Baktur et al., 2013). Collagen can also be crosslinked with flakes of graphene oxide (GO) by 1-ethyl3-(3-dimethylaminopropyl) carbodiimide hydrochloride (EDC) (Kang et al., 2015), generating scaffolds with an elastic modulus $(38.7 \mathrm{kPa})$ comparable to that of developing bones $(\geq 30 \mathrm{kPa}$ in osteoids) (Lo et al., 2000) and higher than that of unmodified collagen $(14.6 \mathrm{kPa})$. The enhanced matrix stiffness over-activated FAK and ERK intracellular signaling pathways in cultured MSCs, boosting the focal adhesion formation, cytoskeletal tension, proliferation rate, and osteogenic differentiation via increased 
expression of ALP and OP. Among naturally derived polymers, GAGs, and silk fibroin are the most frequently used in collagen composites (Farrell et al., 2006; Wang et al., 2011; Alhag et al., 2012). Especially, GAGs generate suitable collagenous 3D environments for the osteogenic stimulation of MSCs, with promising results for bone tissue regeneration both in vitro and in vivo (Farrell et al., 2006; Tierney et al., 2009; Alhag et al., 2012).

Also serving as basic scaffold components alone (like collagen) as well as reinforcement elements in scaffolds constituted of other materials, various biodegradable synthetic polymers (such as PCL, PGA, PLA, PVA, PET, etc.) have been extensively employed to fabricate collagenous BTE materials (Fujita et al., 2005; Stratton et al., 2016; Weisgerber et al., 2016; Zhang et al., 2017). Importantly, a HA-Col-PCL composite scaffold with unique nano-micro-macro hierarchical structure was prepared by Wang J. et al. (2015). A PCL support, manufactured by means of a rapid prototyping technology, provided a macroporous framework further filled with collagen. In turn, collagen offered a microporous architecture where HA nanocrystals were deposited via biomimetic mineralization. Beyond displaying a compressive modulus similar to cancellous bone $(68.75 \pm 3.39 \mathrm{MPa})$ falling within the suggested value range for BTE (10-1,500 MPa) (Hollister, 2005), this composite showed remarkable osteoinductive properties and rapid bone regeneration in a rabbit radius model. To further increase their interaction with the hydrophilic collagen, the hydrophobic synthetic polymers can be chemically modified. For example, surface activation of PLA fibers with diamine and glutaraldehyde induced stronger interaction between the two phases, resulting in an increased compression modulus of collagen, in which the cells spread and attached more efficiently (Hiraoka et al., 2003).

\section{Sources of collagen and commercial biocomposites for BTE}

Various collagen types are found in the tissues of mammals, reptiles, fishes, etc. (Nomura et al., 1996; Wood et al., 2008; Pati et al., 2010; Addad et al., 2011; Parenteau-Bareil et al., 2011; Ferreira et al., 2012; Kim et al., 2013; Ferraro et al., 2017; Felician et al., 2018; León-López et al., 2019). In the mammalian body, the tendon and the skin, rich in fibrous collagen, are used as main sources for collagen extraction (Ferreira et al., 2012). Even though collagen sponges obtained from bovine, ovine, and porcine tendon have reported to share similar physicomechanical properties (Ghodbane and Dunn, 2016), it has to be mentioned that, in general, the xenograft origin represents a key factor determining the cultural accommodation of biomedical products (Easterbrook and Maddern, 2008).

Some sponges are commercially available for the treatment of long bone fractures (Garg et al., 2012; Kuttappan et al., 2016). InFuse is a collagen sponge marketed by Medtronic Sofamor Danek (Memphis, TN) in the U.S., serving as carrier for BMP in clinical therapy of spinal fusion. Also an osteoconductive matrix made of crosslinked collagen type I fully coated with HA, named Healos and distributed by DePuy Orthopedics, Inc. (Warsaw, IN), is applied in spinal fusion treatment. Biomend is a collagen membrane conventionally used in the regeneration of periodontal tissue, commercialized by Integra Lifesciences Corp. (Plainsboro, NJ). Despite the risk of possible iatrogenic transmission of prion-related diseases to patients treated with bovine grafts (Kim et al., 2013), collagen type I of bovine origin has been predominately applied in BTE (Ferreira et al., 2012; Ferraro et al., 2017). In 1993, Collagraft ${ }^{\mathrm{TM}}$ (Collagen Corp., USA), namely HA and TCP-enriched bovine collagen seeded with the patient's bone marrow, received the FDA approval becoming the first collagen-based implant for bone. In parallel, other xenograft types have been investigated (Salamanca et al., 2018). Collapat $\AA$ (BioMet Inc.) is a composite of HA and type I collagen from the calf skin recommended for the treatment of aseptic enclosed metaphyseal bone defects. Its application accelerates the bone regeneration rate of five times, such that a complete closure of rabbit femoral defects can be achieved in 4 weeks (Katthagen and Mittelmeier, 1984; Yunus Basha et al., 2015). Composed of porcine type I and type III collagen fibers, BioGide (GeistlichPharma AG, Wolhusen, Switzerland) is the most eminent commercial collagen membrane, showing marked regenerative abilities in several rat studies (Zhao et al., 2000; Taguchi et al., 2005).

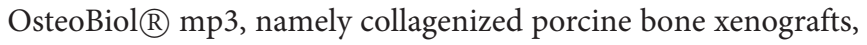
proved to be biocompatible, bioabsorbable, and osteoconductive over a 4-month period following their insertion in rabbits' tibiae (Calvo Guirado et al., 2013). Other FDA approved orthopedic products based on highly purified type I collagen from cattle include composite matrices processed into strips, blocks, and pads for bone grafting procedures (OssiMend $($ ) Bioactive Moldable Strips, purchased from Collagen Matrix, Inc. New Jersey, USA) and fibrillar collagen dental dressing (Collatene $^{\mathrm{TM}}$ Fibrillar Collagen Dental Dressing, commercialized by Ace Surgical Supply Co., Inc., MA, USA) (Ferreira et al., 2012; Salamanca et al., 2016, 2018). GMP-grade constructs for the treatment of degenerative bone disease with limited involvement of skeletal tissue are obtained from Gingistat $\AA$ (Vebas, Milan, Italy), a clinical grade biomimetic sponge made of lyophilized collagen of equine origin (Donzelli et al., 2007). Gingistat ${ }^{\circledR}$ has been chosen as basic material for regenerative constructs opposing to alveolar bone resorption in the periodontal disease (Salvadè et al., 2007).

\section{Advanced biological functions of collagen scaffolds}

Current studies investigate: (i) integrated approaches combining more than one material with the collagen structures, (ii) loading with various cells, and (iii) enrichment with biofactors. The interaction of osteoblasts, pre-osteoblasts, and SCs with collagen inside BTE constructs was characterized in vitro and confirmed with in vivo proofs of principle. In injectable form, collagen hydrogel is a useful delivery platform for bioactive molecules (mostly, chemicals and proteins, but also nucleic acids). This is due to its ability to swell without disintegrating and to incorporate hydrophobic drugs, as well as to a tuned degradation rate allowing for a controlled release. Release profiles of bFGF from collagen hydrogels were monitored and studied in relation to the proliferation ability and osteogenesis of seeded MSCs (Oh et al., 2012), leading to the identification of an optimal bFGF dosage $(10 \mathrm{ng} / \mathrm{ml})$ for the preparation of highly stimulatory constructs. In another study, the spatial immobilization of bone morphogenetic protein-4 (BMP4) into collagen-PLGA hybrid 
platforms improved Ca deposition and expression of osteogenic marker genes (such as type 1 collagen, OPN, and OCN) after in vivo ectopic implantation ( $\mathrm{Lu}$ et al., 2012). In addition, silicified collagen scaffolds loaded with SDF-1 formed bone upon subcutaneous implantation (Niu et al., 2012). Confirming results from in vitro transwell migration experiments, in which both MSCs and endothelial progenitor cells (EPCs) showed improved migration with higher concentrations of released factor, cell-free SDF-1 containing hydrogels stimulated cell-homing in vivo and enhanced blood vessel formation.

\section{Gelatin}

\section{Structure and characteristics}

Gelatin derives from an irreversible hydrolysis of collagen, reducing $300 \mathrm{kDa}$ protein fibrils into smaller peptides, whose molecular weight range varies depending on the chosen denaturation method (Young et al., 2005). The amino acid content of gelatin reflects that of collagen, namely 19 amino acids, with prevalence of glycine, proline, and hydroxyproline. Due to a good degradability, solubility, biocompatibility, and easy supply, gelatin is widely used in biomedicine (Echave et al., 2017). It presents lower antigenicity with respect to complete collagen. Moreover, collagen is rich in RGD residues, namely Arg-Gly-Asp tripeptide sequences known to promote cellular adhesion, but these only become accessible after fiber processing or degradation (Barczyk et al., 2010). Its denaturation to gelatin reveals RGD sequences favoring adhesion, proliferation, and differentiation of cells. Furthermore, gelatin also maintains a matrix metalloproteinase (MMP) recognition sequence enabling enzymatic degradation (Van Den Bulcke et al., 2000). Its chemical and physical properties can be tuned flexibly to meet the requirements of various applications. For instance, the isoelectric point can vary depending on the processing method (acidicprocessing or alkaline pre-treatment processing), yielding either a basic or an acidic gelatin with positive and negative surface charges, respectively (Young et al., 2005). Crosslinking by glutaraldehyde immersion induces mechanical strengthening of the gelatin electrospun fibers, exhibiting almost a 4 -fold higher value of Young's modulus as compared to integral collagen (174 vs. $52 \mathrm{MPa}$ ) (Matthews et al., 2002; Huang et al., 2004).

\section{Manufacturing of biocomposites and their properties}

Nanofibers of gelatin have been produced via electrospinning also by applying a water based co-solvent approach (Song et al., 2008). Different concentrations of HA were combined with gelatin electrospun fibers to fabricate scaffolds for investigation of the fate of human fetal osteoblasts (Salifu et al., 2017). PCL and gelatin have been co-assembled into nanofibers used in BTE applications (Naghieh et al., 2017). Biodegradable grafts for bone defect treatment based on injectable enzymatic cross-linkable gelatin combined with functionalized gold nanoparticles have also been proposed, which also could serve as a good template for drug and cell delivery for TE (Lee et al., 2018). Varying the proportion among components in the formulations of gelatin composites with chito-olisaccharides (COS) and magnesium calcium phosphate (MCP) was found to regulate the scaffolds' pore size with a direct effect on osteogenic differentiation (Ratanavaraporn et al., 2011; Hussain et al., 2012).

\section{Chemical modification}

Certain shortcomings, such as the insufficient thermostability and the potential poisonousness of chemical crosslinking, can be overcome by functional modification of the gelatin structure. One of the most interesting modified gelatin is obtained by reaction with methacrylic anhydride (MA) (Van Den Bulcke et al., 2000). A large number of amino groups exposed on the side chains of gelatin are thereby replaced by methacryloyl groups. MA-gelatin acquires the capacity to photo-crosslink, producing hydrogels with excellent thermostability. These have recently emerged for their applicability in BTE, either alone or in combination with other biomaterials (Heo et al., 2014; Zuo et al., 2015; Celikkin et al., 2018; Raina et al., 2019). Studies concerning the bone mineralization have been carried out with MA-gelatin hydrogels. Zhou et al. claimed a control of the mineralization by the degree of methacrylation, while Zuo et al. developed and compared two distinct methods (i.e., circle-and-cross and a layer-by-layer methods) to build osteon-like structures in bionic bones (Zuo et al., 2012; Zhou et al., 2014).

\section{Chitosan}

\section{Structure and characteristics}

Chitosan (CS) is a natural polysaccharide deriving from chitin, the major component of crustacean exoskeleton (Khor and Lim, 2003; Levengood and Zhang, 2014). It consists in a copolymer of $(1 \rightarrow 4)$-2-acetamido-2-deoxy- $\beta$-D-glucan $(\mathrm{N}$ acetyl D-glucosamine) and ( $1 \rightarrow 4)$-2-amino-2-deoxy- $\beta$-D-glucan (D-glucosamine). CS is commonly extracted from marine crustacean shells through chemical hydrolysis (which accounts for subsequent phases of demineralization, deproteinization, discoloration, and deacetylation), but it can also be isolated by enzymatic digestion of the cell walls of certain fungi (Shahidi and Abuzaytoun, 2005; Cai et al., 2006; Kim and Rajapakse, 2005). The cationic nature of CS favors the interaction with negatively charged molecules like GAGs, proteoglycans, and other nutrients. Despite a lack of mechanical strength, a fast degradation rate and the absence of cell signaling molecules, CS is a biodegradable and biocompatible material owing adhesive and antibacterial properties, particularly appealing in wound healing (Khor and Lim, 2003). Nevertheless, the combination with polymers, cells, and bone-inducing factors can impart osteogenicity (Martins et al., 2010).

\section{Manufacturing and properties of CS scaffolds}

Being structurally similar to GAGs, CS was found suitable to manufacture highly porous scaffolds with interconnected pores, with good bone ECM-mimicking ability and permissive to bone ingrowth into the graft (Khor and Lim, 2003; Di Martino et al., 2005; Pang et al., 2005). CS can be easily shaped into various forms like sponges, films, fibers, beads, and more complex structures for orthopedic applications. Porous CS materials can be obtained simply by freezing and lyophilizing CS acetic acid solutions (Madihally and Matthew, 1999). During lyophilisation, drying removes ice crystals creating a porous structure, where 
pore size can be regulated by a tight control of the temperature. Electrospinning can create CS nanofibers that thanks to their unique characteristics (including high surface area to volume ratio, porosity, permeability, stability, and similarity to that of ECM) have a significant superiority over other morphologies (Balagangadharan et al., 2017).

\section{Biocomposites for BTE}

CS has also been applied as injectable biomaterial for BTE, for instance as composite formulation with $\beta$-TCP and platelet rich plasma (PRP) (Bi et al., 2010), which contains a number of growth factors (i.e., bFGF, PGDF, TGF- $\beta$, IGF, and VEGF). Besides inducing higher ALP activity and osteogenic markers expression in vitro, CS-TCP-PRP efficiently repaired osseous defects in goat tibiae with radiologically evident effects after 16 weeks. As for other natural polymers, compositions with reinforcements and stimulating factors (like HA cement, alginate, hyaluronic acid, calcium phosphate, PMMA, PLA, and growth factors) has been a promising strategy to overcome the mechanical weakness and the lack of osteoinductive properties (Liu et al., 2006; Thein-Han and Misra, 2009; Venkatesan and Kim, 2010; Saravanan et al., 2011). In particular, the association with HA and other bioactive ceramics has become very popular (Venkatesan and Kim, 2010). Mouse osteoblasts (MC3T3-E1) and L929 cells adhere well and proliferate in CScalcium phosphate specimens (Xu and Simon, 2005; Oliveira et al., 2006). In scaffolds composed of CS and poly(butylene succinate) (PBS) with elevated porosity and interconnectivity (59 and $60.9 \%$, respectively), and with pore diameter of $145 \mu \mathrm{m}$, the MSC viability and ALP activity increased during 3 weeks of in vitro culture, and elevated rate of bone formation was observed in murine cranial, critical-size bone defects (CostaPinto et al., 2012). Higher porosity (around 97\%) with an average pore size of $100 \mu \mathrm{M}$ was achieved in CS-alginate systems (Florczyk et al., 2013), where the addition of proteins and other factors, like bone marrow aspirate or BMP-2, demonstrated good bone regeneration in a calvarial defect rat model. In general, morphogenic factors and drugs can be delivered in a controlled fashion from CS by virtue of its favorable gelling and degradation properties. CS allows for slow release of BMP- 2 and TGF- $\beta$ 2 in coatings covering the allografts in experimental cranial critical size defect models (Canter et al., 2010). In another study, scaffolds fabricated from CS and bovine-derived xenograft (BDX) at 40:60 ratio supported the in vitro proliferation and differentiation of bone marrow-derived MSCs (BM-MSCs) from the human jaw (Zang et al., 2017), that can be intraoperatively collected from alveolar bone during dental surgery (i.e., crown lengthening surgery and wisdom tooth extraction). To treat not self-repairing bone defects (like burr holes in craniotomy), certain CS-based systems have been designed (Shirosaki, 2012). CS- $\gamma$-glycidoxypropyltrimethoxysilane (GPTMS) hybrid can be prepared via sol-gel method, and further completed with HA by soaking in an alkaline phosphate solution, promoting skull bone formation in vivo (Shirosaki et al., 2018). Long-term studies conducted over 2 to 3 years to assess the outcome of implantation of CS-siloxane hybrids in skull bone regeneration revealed that new regenerated tissues completely closed the defect, but with a thickness inferior to the normal skull thickness (Shirosaki et al., 2018). CS functioned as effective system for slow, controlled release of BMP-2 and TGF- $\beta-2$ in coatings covering allografts in experimental cranial critical size defect models (Canter et al., 2010).

\section{Chemical modification}

The chemical modification of CS is reported to stimulate cell proliferation and ALP activity in different systems. For instance, CS glutamate and HA containing cultured osteoblasts from bone marrow aspirate efficiently repaired bone defects in $8 \mathrm{~mm}$ diameter cranial defects in rat calvaria (Mukherjee et al., 2003), as assessed in terms of mineral density found in the lesion sites. In another study, the immobilization of peptides was shown to contribute to bone formation (Qu et al., 2010): when decorated with RGD peptides, CS-HA scaffolds displayed $88.4 \%$ porosity with average pore size of $400 \mu \mathrm{m}$, and promoted osteogenesis via enhanced cell adhesion. In fact, the observation of significantly higher ALP activity suggests that engineering of optimized cell attachment sites is highly beneficial to the differentiation.

\section{Biocomposites with nano-objects}

CNTs have emerged as a special class of reinforcement fillers for CS nano-composites, thanks to their ability to drastically increase the mechanical strength (Wang et al., 2005). Moreover, they were found to have good bone tissue compatibility and capability to accelerate bone formation under stimulation with recombinant hBMP-2 (Usui et al., 2008). The incorporation of metallic nano-objects has also been reported. Doping with inert $\mathrm{TiO}_{2}$ nanoparticles transforms CS into highly porous, brittle and effective BTE substitute with a density $\left(1.2870 \mathrm{~g} / \mathrm{cm}^{3}\right)$ comparable to that of dry bone $\left(0.8-1.2 \mathrm{~g} / \mathrm{cm}^{3}\right)$ (Kumar, 2018).

\section{Matrices for gene delivery}

Much of the appeal of CS relies on the presence of repeating units rich in primary amine groups easily becoming protonated under acidic conditions. Thanks to this feature, CS became a relevant vector for non-viral gene delivery transfecting a number of cell types (Raftery et al., 2013). In fact, the cationic nature of CS elicits an efficient complexation with DNA molecules making it an ideal candidate for gene delivery (Di Martino et al., 2005). Successful CS-pDNA complexation and sustained transfection of MSCs makes CS a promising vector also for gene activated matrices (GAMs), which are scaffolds engineered to provide a direct and sustained delivery of nucleic acids ensuring efficient and durable cell transfection in situ (Raisin et al., 2016; D'Mello et al., 2017; Lin et al., 2017). In particular, the encapsulation of plasmids into nano or micro-particulate CS-systems to be loaded within scaffolds could offer significant spatiotemporal control on the activity of the encoded biofactors (Peng et al., 2009).

\section{Current use}

By virtue of its water retention, protein adsorption, mechanical strength, porosity, biocompatibility, biomineralization, and biodegradability, CS has drawn attention in BTE. However, its actual applicability is limited by some disadvantages, including immunogenicity and arduous electrospinning processing (Bellich et al., 2016). Moreover, further studies focusing on long-term in 
vivo application are still needed to validate the in vitro findings regarding CS properties.

\section{Alginate \\ Structure and characteristics}

As the most abundant marine biopolymers, alginates comprise a broad family of polysaccharides found in brown seaweeds. Even if they can be produced also by some bacteria (e.g., Azotobacter and Pseudomonas species), the cell wall and intracellular space of seaweeds (Laminaria sp., Macrocystis sp., Lessonia sp., and others) remain the major sources. Alginates are linear unbranched polymers containing $\beta$ - $(1 \rightarrow 4)$-linked $D$ mannuronic acid $(\mathrm{M})$ and $\alpha$-( $(1 \rightarrow 4)$-linked L-guluronic acid $(\mathrm{G})$ residues. The overall polysaccharide sequence contains blocks of consecutive $G$ and $M$ residues, or alternating MG residues. Sodium alginate is the main form of alginate used. The ability of alginates to form soft hydrogels in the presence of $\mathrm{Ca}^{2+}$ relies on the participation of G-blocks in intermolecular cross-linking with divalent cations (Venkatesan et al., 2014b).

\section{Manufacturing and properties of alginate scaffolds for BTE} Alginates can be shaped into a number of soft biomaterials including films, nanoparticles, foams, elastic gels, fibers, and multilayers stable in physiological conditions, which ensures the preservation of cell viability and function. Sodium alginate hydrogel was used as the carrier for dual delivery of BMP-2 and bFGF showing a sustained release ability supporting the proliferation and osteogenic differentiation of BM-MSCs inside nano-composite polymeric scaffolds (PLGA-PCL-nanoHA) loaded with vascular stents for large bone defect regeneration in rabbit mandibles (Su et al., 2013). Other alginate composites have been investigated, complemented with polymers (PLGA, PEG, and chitosan), proteins (collagen and gelatin), ceramic, biosilica, bioglass, and peptides (Venkatesan et al., 2015). Apart from physico-mechanical improvement, composites impart more marked biological effects on the seeded cells, in terms of cell affinity, osteogenic differentiation, and biomineralization. Scaffolds with highly porous and interconnected structures were manufactured by subjecting alginate-HA composite to internal gelation followed by freeze-drying (Marsich et al., 2013). In 2010, Suárez-González et al. described a simple method to control the nucleation of a bone-like HA mineral onto macroporous alginate scaffolds by incubation in modified SBFs for 4 weeks (SuárezGonzález et al., 2010), and reported improved MSC attachment. Freeze drying is the dominant technique to manufacture CSalginate hybrids for BTE (Venkatesan et al., 2014b), whereas in situ co-precipitation elicits the integration of HA crystals (Jin et al., 2012). Rapid bone formation and vascularization were observed in these hybrids, characterized by enhanced mechanical strength and structural stability (Li et al., 2005). The addition of MSCs and BMP-2 is expected to generate injectable materials able to induce new bone formation in a clinical context (Park et al., 2005). Recently, a polypyrrole-alginate blend was incorporated into chitosan via lyophilisation to obtain a scaffold supporting the growth of MG-63 cells under electrical stimulation within a bioreactor system, to evaluate the role of a substrate endowed with conducting properties in bone regeneration (Sajesh et al., 2013).

\section{Biocomposites with nano-objects}

Among antimicrobial agents, silver induces disruption of bacterial cell membranes and inhibits DNA replication, enzymatic activity, and ATP production (Rai et al., 2001; Lara et al., 2011). Due to the high surface-to-volume ratio, nano-objects display a reactivity higher than the bulk element. Therefore, shaping the silver into nanoparticles further augments its bactericidal activity on different strains of clinical relevance (Rai et al., 2001; Alt et al., 2004; Chaloupka et al., 2010). Silver nanoparticles adsorbed on top of alginate scaffolds exert a strong bactericidal effect against both Gram + and Gram- bacterial strains (Marsich et al., 2013). With a total porosity of around $94 \%$ and pore size of $130-170 \mu \mathrm{m}$, tricomponent scaffolds consisting of alginate, HA, and CNTs demonstrated enhanced proliferation, differentiation, and attachment of an osteosarcoma cell line (MG-63), and were therefore suggested for BTE applications (Rajesh and Ravichandran, 2015). A nanocomposite scaffold of GO, gelatin and alginate with high swelling $(\sim 700 \%)$ and slow biodegradation rate ( $\sim 30 \%$ in 28 days) was obtained, where MSCs displayed elevated expression of osteoblast transcription factors (Runx2 and OCN) and ALP activity, suggesting good osteoinductivity (Purohit et al., 2019).

\section{Micro-constructs}

By aggregation, it is possible to prepare highly porous scaffolds from alginate microbeads and microfibers, where the biological tissue development benefits from the open structure with positive outcome on vascularization, oxygenation, cell migration, adhesion, and proliferation (Valente et al., 2012). Indeed, alginate is well-suited for the production of microspheres for the encapsulation and delivery of cells and proteins (Somo et al., 2017; Dhamecha et al., 2019). Single layered and multilayered microbeads can assemble from alginate at neutral $\mathrm{pH}$ and mild temperatures through conventional external gelation protocols, in which vortexing, homogenization, ultrasonication, spray drying, or other instrumental manipulation differentially affect the overall particle characteristics (Dhamecha et al., 2019). Alginate microspheres encapsulating adipose-derived stem cells (ADSCs) or human osteoprogenitors (HOP) from BM-MSCs co-cultured with human umbilical vein endothelial cells (HUVECs) were made osteogenic and angiogenic by enrichment with PRP or grafting with RGD peptides (Grellier et al., 2009; Man et al., 2012). These systems are ideal candidates for the development of micro-invasive bone regeneration applications. Qiao et al. seeded mouse osteoblasts into alginateCS microcapsules, complexed with calcium phosphate cement (CPC) to assess the osteogenic potential of the resulting paste and trace the implanted cells in vivo (Qiao et al., 2013). After 4 weeks of subcutaneous implantation, new collagen formation, lamellar bone-like mineralization and angiogenesis were observed, while at 8 weeks collagen expansion and osteoid-like structures were noticed. Similarly, human embryonic stem cells-derived MSCs were encapsulated in alginate microbeads inside macroporous $\mathrm{CPC}$ constructs, holding promise for bone regeneration in a wide 
range of orthopedic and maxillofacial applications (Tang et al., 2012). Moshaverinia et al. conducted in vitro studies to assess viability and osteogenic differentiation of MSCs from periodontal ligament and gingiva (PDLSCs and GMSCs), encapsulated into oxidized alginate microbeads constituting an injectable and biodegradable scaffold for BTE (Moshaverinia et al., 2012). In an attempt to mimic the composition of bone, gradual mineralization was also achieved by co-immobilizing stem cells and ALP into alginate beads (Westhrin et al., 2015).

\section{Modified alginate with advanced biological functions}

Alginate has been structurally modified to host a variety of functionalities. For instance, peptides containing RGD or PHSRN (proline-histidine-serine-arginine-asparagine) sequences from fibronectin were grafted on alginates in order to create functionalized gels that more closely recapitulate the chemistry of natural cell adhesive proteins and may be useful in developing optimized BTE scaffolds (Nakaoka et al., 2013). In another study, alginate scaffolds seeded with human BM-MSCs demonstrated enhanced bone regenerative capability in critically-sized femur defects in mice through a fine temporal control on the release kinetics of bioactive factors (Kanczler et al., 2010a). In fact, alginate-PLA hybrids, generated through a supercritical $\mathrm{CO}_{2}$ /alginate entrapment technique, were characterized by distinct biodegradation rates of the two components. As a consequence, they could release selected factors at different rates, with a rapid delivery of VEGF by alginate fibers as readily degradable carrier in contrast to a slower release of BMP-2 occurring from the synthetic polymer. Kolambkar et al. went a step further by designing a strategy for spatiotemporal control of growth factor delivery based on a hybrid system in which an injectable alginate hydrogel was used for rhBMP-2 delivery, while an electrospun nanofiber mesh served for guiding bone regeneration in critically-sized segmental defects in a rat model (Kolambkar et al., 2011).

\section{Current use}

Even though alginate has been declared safe for application in humans by the U.S. Food and Drug Administration (FDA) (de Vos et al., 2014; Xu and Lam, 2018), no devices for BTE have been commercialized so far. Interestingly, the use of alginates as bioinks for bioprinting is thought to be a valid opportunity for these hydrogels to expand their application in BTE (HernándezGonzález et al., 2020).

\section{Silk Proteins}

\section{Structure and characteristics}

Silk is a protein fiber secreted by arthropods like silkworms and spiders. It is composed of a structural core component, fibroin, and a hydrophilic protein coating made of sericin. The silk fibroin (SF) is a fibrous protein owing unique mechanical properties, environmental stability, morphologic flexibility, tunable proteolytic biodegradability, along with the ability to support the osteogenic differentiation of MSCs.

\section{Manufacturing and properties of silk scaffolds for BTE}

SF can be molded into diverse forms, chemically modified and combined synergistically with other minerals and polymers (Melke et al., 2016; Yao et al., 2016; Bhattacharjee et al., 2017). Films are obtained by layer-by-layer deposition or casting, whereas hydrogels by sol-gel transition or crosslinking. Fiber deposition and electrospinning are the most conventional options to shape SF into non-woven mats. Finally, particulate leaching, gas foaming, rapid prototyping (3D printing) and freeze drying render can generate $3 \mathrm{D}$ porous structures scaffolds (Bhattacharjee et al., 2017). Macroporous SF scaffolds, fabricated by water- or solvent-based procedures, displayed new bone formation at 8 weeks after implantation in defects of tibia and humerus cancellous bone in a sheep model (Uebersax et al., 2013). By adding BMP-2 into SF solution before electrospinning, a fibrous biomaterial with improved repair ability was created by Li et al. (2006).

\section{Biocomposites, particles, and chemical modification}

Since SF porous scaffolds and hydrogels often fail to match the mechanical demands of BTE, reinforcement strategies have been adopted in many works. Beyond conventional reinforcing materials (HA, BGNs, polymers, etc.), also SF microparticles were employed to such scope, increasing the compressive modulus of SF hydrogels over6-folds in a 1:2 (matrix:particle) mixture, which in turn enhanced the osteogenic performance of MSCs as well as the calcium adsorption (Rockwood et al., 2011). Moreover, silk particulate can function as template for mineralization and sustainable delivery of growth factors. SF modification with PRP, endothelial nitric oxide, IGF-I, or adenoviruses carrying BMP7-encoding DNA has been proposed to prompt and strengthen silk scaffolds' osteointegration (Bhattacharjee et al., 2017). One limiting factor in the use of SF is the co-existence of sericin with fibroin in the native silk fiber, which may trigger antigenic reaction (Meinel and Kaplan, 2012). This shortcoming can be overcome by adjusting the silk processing procedure with physical and/or chemical modifications, or incorporation of other polymers/minerals (Bhattacharjee et al., 2017).

Also, the very same soluble sericin extracted from native silk fibers was considered in BTE for its ability to mediate the formation of HA crystals in SBF, in turn stimulating adhesion, proliferation, and osteogenic differentiation of human BM-MSCs (Yang et al., 2014; Jiayao et al., 2017).

\section{Current use}

Even though, due to continuing fast-paced progress, several silkdevices are expected to be added to practice in wound dressing or orthopedic implants, currently none has yet proceeded to human trials.

\section{Hyaluronic Acid}

\section{Structure and characteristics}

Hyaluronic acid (HAc) is a glycosaminoglycan containing repeating disaccharide units of $\mathrm{N}$-acetyl-D-glucosamine and D-glucuronic acid. Synthesized by hyaluronan synthases, it is a primary component of the ECM of the human connective tissue and the simplest one among the various GAGs 
(Hemshekhar et al., 2016). Thanks to its biocompatibility, ease of chemical functionalization, degradability, hydrophilicity, non-immunogenicity, and presence in the cytoplasm of osteoprogenitors, HAc has been used in BTE (Zhao et al., 2016).

\section{Chemical modification}

The solubility and availability of reactive functional groups facilitate HAc chemical modifications. For instance, thiolmodified HAc combined with polyethylene glycol (PEG) provided biphasic release kinetics of BMP-2 accounting for an initial burst followed by a sustained release and leading to ectopic bone formation (Bhakta et al., 2013). In another research, by conjugating 2-aminoethyl methacrylate (AEMA) to HAc via amide bonds, followed by mixing with a cytocompatible photoinitiator (Irgacure D-2959) and irradiation under $365 \mathrm{~nm}$ UV light, Bae et al. prepared photo-cured hydrogels carrying the growth and differentiation factor 5 (GDF5) and simvastatin, which significantly improved osteogenesis (Bae et al., 2011, 2014).

\section{Current use}

It was found that Hyaloss ${ }^{\mathrm{TM}}$, a HAc-based matrix, mixed with autologous bone accelerated bone formation and remodeling in post-extractive sites (Baldini et al., 2010), whereas ChronOS inject, a resorbable bone void filler made of HAc and TCP, proved to be successful in curing benign bone cysts (Joeris et al., 2010). Nevertheless, even if increasing attention is given on a clinical use of HAc, well-designed clinical randomized controlled trials with long follow-ups are still needed to judge its actual effectiveness in dentistry and bone repair (Zhao et al., 2016).

\section{Other Natural Polymers}

Other natural polymers widely used for TE of other organs are explored in bone repair.

\section{Fibrin}

Produced from fibrinogen, fibrin is a protein matrix containing sites for cell binding, which has been investigated as a substrate for cell adhesion, spreading, migration, and proliferation (Ahmed et al., 2008). Besides being immune-compatible and owing haemostatic, chemotactic, and mitogenic properties, fibrin enables the fabrication of completely autologous scaffolds, given that its precursors, thrombin and fibrinogen, can be extracted from the peripheral blood of patients (Noori et al., 2017). For instance, autologous fibrin glue has found extensive application in regenerative maxillofacial surgery (Khodakaram-Tafti et al., 2017).

\section{Self-assembling peptides}

Hydrogels self-assembled from gelation of self-complementary amphiphilic peptides are a novel class of TE biomaterials. Peptides can easily be modified to contain bioactive motifs, such as phosphoserine residues or RGDS peptides beneficial for mineralization and cell adhesion respectively (Mata et al., 2010; Visser et al., 2016). TCP minerals and peptide hydrogels act synergistically to enhance bone regeneration in a non-critical sized defect in rat femurs (Amosi et al., 2012). A commercially available peptidic hydrogel, Puramatrix ${ }^{\mathrm{TM}}$, can support the osteogenic differentiation route of dedifferentiated cells derived from subcutaneous fat through minimally invasive procedures. Varying the concentration of Puramatrix ${ }^{\mathrm{TM}}$ in the hydrogel enables to control the matrix stiffness, affecting MC3T3-E1 osteoprogenitor cell behavior (cell elongation and osteogenesis) (Kishimoto et al., 2011; Marí-Buyé et al., 2013).

\section{Keratin}

Keratin comprises a family of structural, filament-forming proteins found in epidermal and corneous tissues emerging as alternative for design of BTE scaffolds and strategies (Tachibana et al., 2005). The main sources of extraction are human hair, wool, and feathers (Rajabi et al., 2020). For example, keratin osteoconductive porous scaffolds can be engineered (Arslan et al., 2017). Carriers with tunable erosion rates were formulated by varying disulfide crosslinking ratios of oxidatively (keratose) to reductively (kerateine) extracted keratin. Such carriers released rhBMP-2 in vitro and mediated heterotopic bone formation in mice (Cohen et al., 2018).

\section{Gellan gum}

Gellan gum derived from bacterial fermentation (Sphingomonas group) forms injectable and thermoreversible hydrogels with tunable mechanical properties useful for preparation of bilayered scaffolds for osteochondral regeneration (Pereira et al., 2013; Manda et al., 2018).

\section{Spongin}

As analogous to vertebral collagen type XIII, spongin, the main organic component of sponge fibrous skeletons, has emerged as excellent alternative source of collagen proteins for BTE scaffolds due to the lower risk of transmission of infectioncausing agents (Granito et al., 2016). Human osteoprogenitors can attach, aggregate, and grow at sustained rate on collagen fibers of the skeleton of an undetermined species of Spongia (Spongiidae family) (Green et al., 2003).

Finally, other polysaccharides (like dextran, cellulose, starch, carrageenans, or agarose) and proteins (like heparin or chondroitin sulfate) with relevance for BTE, are listed in Table 3 (Chung and Park, 2007; Martins et al., 2009; Garg et al., 2012; Khan and Ahmad, 2013; Sayin et al., 2014; Shi et al., 2016; Farrugia et al., 2018; Nikpour et al., 2018; Sofi et al., 2018; Witzler et al., 2019; Yegappan et al., 2019). Physico-mechanical characteristics of various composites based on natural polymers are compared in Table 4.

\section{FUTURE PERSPECTIVE AND CONCLUSIONS}

Being very similar or identical to endogenous macromolecules, natural polymers are optimal constituents for implantation, not only because the biological environment is prepared to recognize and metabolically process them, but also because they enable to tailor the biomaterial functions at the molecular level (Yannas, 2004; Jahan and Tabrizian, 2016). The fact that natural polymers are degraded by naturally occurring enzymes virtually guarantees that after implantation, the constructs will be eventually resorbed through physiological processes (Yannas, 2004; Bhatia, 2016). 
Cross-linking and other strategies of chemical modification enable the designer to control the lifetime of the implant, with important impact in the applications where scaffolds are supposed to deliver a specific function over a precise period of time before being replaced by newly formed tissue (Lee and Shin, 2007; Lee and Yuk, 2007; Bhatia, 2016; Salehi-Nik et al., 2017). However, this natural feature carries certain limitations. As compared to the synthetic polymers, the natural ones owe much more complex structures requiring elaborated technological manipulation, and almost inevitably, their modification, as well as the physico-chemical methods to isolate them from tissues, can significantly alter their native conformation (Yannas, 2004). Accounting for an enormous variability among species and functional compartments (i.e., species and tissue specificity), macromolecules of animal derivation also make it necessary to implement stringent control procedures on the nature of the raw material in order to ensure adherence to quality and uniformity specifications among different batches. Due to their similarity to natural substances, TE proteins are strongly immunogenic, such that modification of antigenic determinants is often needed to impart integrity and long duration of the implant (Yannas, 2004; Titorencu et al., 2017). Besides being far more immunogenic than sugars and other polymers, proteins also pose a precise challenge in terms of manufacturing. The pyrolytic modification and the decomposition usually occurring when exceeding the melting temperature preclude the application of thermoplastic processing at high temperature (like melt extrusion), and make it necessary to implement alternative methods for extrusion at room temperature (Yannas, 2004; Wang et al., 2020). On balance, these opposite characteristics result in qualifying the natural polymers as intriguing materials for bioengineering and transplantation, providing unprecedented solutions in BTE (Oliveira et al., 2018).

Based on the collection of studies herein reviewed, one can distinguish the following promising research directions in natural polymeric BTE constructs: (i) strategies of controlled delivery of bioactive molecules to accelerate bone healing, (ii) modification of polymers to optimize the cell-matrix interactions and shape the scaffold topography, and (iii) engineering of GAMs to integrate advanced principles of gene therapy in the science of scaffold design.

One of the most relevant perspectives in polymer science is represented by the creation of functional coatings improving the properties of biomaterials, such as bioceramics, which are ideal bone regeneration platforms by virtue of their drugdelivery ability and apatite-like formation (Mohamad Yunos et al., 2008; Baino et al., 2015). As the surface instability and inherent brittleness in bioglass foams compromise their mechanical strength and cytocompatibility, polymer coatings can be introduced to reduce the degradation rate or improve the interaction with the biological surrounding (Peroglio et al., 2007; Mohamad Yunos et al., 2008; Rehorek et al., 2013). Even though synthetic polymers held a predominant role thus far, the natural ones have started to conquer space in this territory (Mohamad Yunos et al., 2008; Rehorek et al., 2013; Iviglia et al., 2016; Wang J. et al., 2016). For instance, a biodegradable layer of PHB produced by bacteria isolation considerably increased the bioactivity and doubled the compressive strength of glassceramics without altering the interconnectivity of their pore structure (Bretcanu et al., 2009). Coating with pectin-chitosan polyelectrolytes elicited the controlled release of antibiotics from porous scaffolds in order to contrast periprosthetic infections (Iviglia et al., 2016), whereas blending silk with mesoporous bioglass scaffolds was beneficial to stromal cell attachment, proliferation and osteogenic differentiation $(\mathrm{Wu}$ et al., 2010). Besides displaying values of Young's modulus and fracture toughness similar to those of native bone, bioceramics vacuum-coated with alginate promoted osteoblast adhesion and maturation (Torres et al., 2013). The laminin-coating, in addition to amine-surface modification, promoted cell colonization of foams (Tan et al., 2003). Immobilization of natural polymers onto synthetic coating is also possible and functional to enhance the scaffold properties (Wang X. et al., 2016). Major advances in this field of polymer-based BTE are expected in a near future.

In addition, it has been well-documented that the incorporation of nano-sized inorganic particles in natural polymer composites not only leads to incremental cellular adhesion, but can also improve the polymer mechanical properties and osteoconductive ability to a higher extent than micro-sized fillers. In fact, osteogenic cells optimally interact with nanophase minerals and proteins, since they provide larger surface area and create nanoscale roughness (Dobbenga et al., 2016).

Another eminent aspect in the field of BTE scaffold design concerns the opportunity to use the constructs to harness SC fate toward specific lineages. Accordingly, cues for osteogenic induction can be integrated in the scaffold structure and delivered to cells via physical stimuli. For instance, the mechanotransduction signaling pathways in SCs can be activated by tagging magnetic nanoparticles to mechanosensitive membrane receptors and actuating these effectors through electromagnetic fields, inducing osteogenesis (Kanczler et al., 2010b).

Future investigations should also aim at preparing biomaterials with degradation rate matching the bone regeneration rate, integrated with strategies for stimulating scaffold vascularization (e.g., co-cultures, growth factors, etc.) and bioreactor technologies to streamline and improve preimplantation culture. Also, novel procedures for cell biophysical stimulation should be implemented to ease access to clinical use. In fact, despite several successful in vitro and in vivo trials of constructs based on natural polymers, few products are now commercially available or under clinical investigation, such that the translational benefits remain distant from potential patients. Currently, the majority of biological scaffolds with actual relevance in clinical use are those comprising collagens, such as absorbable collagen sponges, porous scaffolds, HA composites and gel foams (Zeng et al., 2018). It has to be mentioned that cultural and religious traditions may limit the acceptance of collagens and other polymers of animal origin: for instance, the Muslim and Jewish beliefs forbid the consumption of pig meat, identifying swine-derived biomaterials as banned. Similarly, followers of the Hindu faith may refuse bovine surgical products. In modern multicultural societies, the implantation of animal polymers must be anticipated by the informed consent process 
to avoid religious distress and possible litigation. Nevertheless, the rhetorical-cultural challenge in getting patients overcoming the prejudices about the material's uncleanliness, impurity, and offensiveness to the religious sensibility cannot be ignored even when developing the scaffolds to the clinical grade in order to predict their actual applicative impact.

In conclusion, it is clear that a deeper knowledge about the dynamics of the bone tissue microenvironment should allow for a proper simulation, likely meeting the open challenges still limiting the natural polymers from entering into BTE clinically. However, these polymers offer a unique chance to create biomimetic biocompatible microenvironments for cells of the osteogenic niche. The strategies for engineering their properties are expected to further augment their clinical potential and become determinant in the design of efficient regenerative matrices to repair the skeletal lesions in the future.

\section{REFERENCES}

Addad, S., Exposito, J. Y., Faye, C., Ricard-Blum, S., and Lethias, C. (2011). Isolation, characterization and biological evaluation of jellyfish collagen for use in biomedical applications. Mar. Drugs 9, 967-983. doi: 10.3390/md9060967

Ahmed, T. A., Dare, E. V., and Hincke, M. (2008). Fibrin: a versatile scaffold for tissue engineering applications. Tissue Eng. Part B Rev. 14, 199-215. doi: 10.1089/ten.teb.2007.0435

Alhag, M., Farrell, E., Toner, M., Lee, T. C., O’Brien, F. J., and Claffey, N. (2012). Evaluation of the ability of collagen-glycosaminoglycan scaffolds with or without mesenchymal stem cells to heal bone defects in Wistar rats. Oral Maxillofac. Surg. 16, 47-55. doi: 10.1007/s10006-011-0299-0

Alt, V., Bechert, T., Steinrucke, P., Wagener, M., Seidel, P., Dingeldein, E., et al. (2004). An in vitro assessment of the antibacterial properties and cytotoxicity of nanoparticulate silver bone cement. Biomaterials 25, 4383-4391. doi: 10.1016/j.biomaterials.2003.10.078

Amosi, N., Zarzhitsky, S., Gilsohn, E., Salnikov, O., Monsonego-Ornan, E., Shahar, R., et al. (2012). Acidic peptide hydrogel scaffolds enhance calcium phosphate mineral turnover into bone tissue. Acta Biomater. 8, 2466-2475. doi: 10.1016/j.actbio.2012.04.003

Arahira, T., and Todo, M. (2016). Variation of mechanical behavior of $\beta$-TCP/collagen two phase composite scaffold with mesenchymal stem cell in vitro. J. Mech. Behav. Biomed. Mater. 61, 464-474. doi: 10.1016/j.jmbbm.2016.04.019

Arakawa, C., Ng, R., Tan, S., Kim, S., Wu, B., and Lee, M. (2017). Photopolymerizable chitosan-collagen hydrogels for bone tissue engineering. J. Tissue Eng. Regen. Med. 11, 164-174. doi: 10.1002/term.1896

Aravamudhan, A., Ramos, D. M., Nip, J., Harmon, M. D., James, R., Deng, M., et al. (2013). Cellulose and collagen derived micro-nano structured scaffolds for bone tissue engineering. J Biomed. Nanotechnol. 9, 719-731. doi: $10.1166 /$ jbn.2013.1574

Armentano, I., Dottori, M., Fortunati, E., Mattioli, S., and Kenny, J. M. (2010). Biodegradable polymer matrix nanocomposites for tissue engineering: a review. Polym. Degrad. Stab. 95, 2126-2146. doi: 10.1016/j.polymdegradstab.2010.06.007

Arslan, Y. E., Sezgin Arslan, T., Derkus, B., Emregul, E., and Emregul, K. C. (2017). Fabrication of human hair keratin/jellyfish collagen/eggshellderived hydroxyapatite osteoinductive biocomposite scaffolds for bone tissue engineering: from waste to regenerative medicine products. Colloids Surf. B Biointerfaces 154, 160-170. doi: 10.1016/j.colsurfb.2017.03.034

Bae, M. S., Ohe, J. Y., Lee, J. B., Heo, D. N., Byun, W., Bae, H., et al. (2014). Photo-cured hyaluronic acid-based hydrogels containing growth and differentiation factor 5 (GDF-5) for bone tissue regeneration. Bone 59, 189-198. doi: 10.1016/j.bone.2013.11.019

Bae, M. S., Yang, D. H., Lee, J. B., Heo, D. N., Kwon, Y. D., Youn, I. C., et al. (2011). Photo-cured hyaluronic acid-based hydrogels containing

\section{AUTHOR CONTRIBUTIONS}

MF conceived the original idea of the manuscript, structured the outline, wrote the main text and prepared figures and tables. GB, $\mathrm{MC}$, and AS edited the final manuscript. All authors approved it for publication.

\section{FUNDING}

This study was supported by the NANOTRANSMED project. The NANOTRANSMED project is co-funded by the European Regional Development Fund (ERDF) and by the Swiss Confederation and the Swiss cantons of Aargau, Basel-Landschaft and Basel-Stadt, in the framework of the INTERREG V Upper Rhine program (Transcending borders with every project).

simvastatin as a bone tissue regeneration scaffold. Biomaterials 32, 8161-8171. doi: 10.1016/j.biomaterials.2011.07.045

Baino, F., Novajra, G., and Vitale-Brovarone, C. (2015). Bioceramics and scaffolds: a winning combination for tissue engineering. Front. Bioeng. Biotechnol. 3:202. doi: 10.3389/fbioe.2015.00202

Baktur, R., Yoon, S. H., and Kwon, S. (2013). Effects of multiwalled carbon nanotube reinforced collagen scaffolds on the osteogenic differentiation of mesenchymal stem cells. J. Nanomater. 2013:7. doi: 10.1155/2013/904083

Balagangadharan, K., Dhivya, S., and Selvamurugan, N. (2017). Chitosan based nanofibers in bone tissue engineering. Int. J. Biol. Macromol. 104, 1372-1382. doi: 10.1016/j.ijbiomac.2016.12.046

Baldini, A., Zaffe, D., and Nicolini, G. (2010). Bone-defects healing by high molecular hyaluronic acid: preliminary results. Ann. Stomatol. 1, 2-7.

BaoLin, G., and Ma, P. X. (2014). Synthetic biodegradable functional polymers for tissue engineering: a brief review. Sci China Chem. 57, 490-500. doi: 10.1007/s11426-014-5086-y

Barczyk, M., Carracedo, S., and Gullberg, D. (2010). Integrins. Cell Tissue Res. 339, 269-280. doi: 10.1007/s00441-009-0834-6

Bellich, B., D’Agostino, I., Semeraro, S., Gamini, A., and Cesàro, A. (2016). "The good, the bad and the ugly" of chitosans. Mar. Drugs 14:E99. doi: 10.3390/md14050099

Bhakta, G., Lim, Z. X., Rai, B., Lin, T., Hui, J. H., Prestwich, G. D., et al. (2013). The influence of collagen and hyaluronan matrices on the delivery and bioactivity of bone morphogenetic protein-2 and ectopic bone formation. Acta Biomater. 9, 9098-9106. doi: 10.1016/j.actbio.2013.07.008

Bhatia, S. (ed.). (2016). "Natural polymers vs synthetic polymer," in Natural Polymer Drug Delivery Systems: Nanoparticles, Plants, and Algae, ed S. Bhatia (Cham: Springer), 95-118. doi: 10.1007/978-3-319-41129-3_3

Bhattacharjee, P., Kundu, B., Naskar, D., Kim, H. W., Maiti, T. K., Bhattacharya, D., et al. (2017). Silk scaffolds in bone tissue engineering: an overview. Acta Biomater. 63, 1-17. doi: 10.1016/j.actbio.2017.09.027

Bhattarai, D. P., Aguilar, L. E., Park, C. H., and Kim, C. S. (2018). A review on properties of natural and synthetic based electrospun fibrous materials for bone tissue engineering. Membranes 8:E62. doi: 10.3390/membranes80 30062

Bhumiratana, S., Grayson, W. L., Castaneda, A., Rockwood, D. N., Gil, E. S., Kaplan, D. L., et al. (2011). Nucleation and growth of mineralized bone matrix on silk-hydroxyapatite composite scaffolds. Biomaterials 32, 2812-2820. doi: 10.1016/j.biomaterials.2010.12.058

Bi, L., Cheng, W., Fan, H., and Pei, G. (2010). Reconstruction of goat tibial defects using an injectable tricalcium phosphate/chitosan in combination with autologous platelet-rich plasma. Biomaterials 31, 3201-3211. doi: 10.1016/j.biomaterials.2010.01.038

Blokhuis, T., and Arts, J. C. (2011). Bioactive and osteoinductive bone graft substitutes: definitions, facts and myths. Injury 42:S26. doi: 10.1016/j.injury.2011.06.010 
Bonani, W., Singhatanadgige, W., Pornanong, A., and Motta, A. (2018). Natural origin materials for osteochondral tissue engineering. Adv. Exp. Med. Biol. 1058, 3-30. doi: 10.1007/978-3-319-76711-6_1

Bretcanu, O., Misra, S., Roy, I., Renghini, C., Fiori, F., Boccaccini, A. R., et al. (2009). In vitro biocompatibility of $45 \mathrm{~S} 5$ Bioglass-derived glass-ceramic scaffolds coated with poly(3-hydroxybutyrate). J. Tissue Eng. Regen. Med. 3, 139-148. doi: $10.1002 /$ term. 150

Bürck, J., Aras, O., Bertinetti, L., Ilhan, C. A., Ermeydan, M. A., Schneider, R., et al. (2018). Observation of triple helix motif on electrospun collagen nanofibers and its effect on the physical and structural properties. J. Mol. Struct. 1151, 73-80. doi: 10.1016/j.molstruc.2017.09.030

Cai, J., Yang, J., Du, Y., Fan, L., Qiu, Y., Li, J., et al. (2006). Enzymatic preparation of chitosan from the waste Aspergillus niger mycelium of citric acid production plant. Carbohydr. Polym. 64, 151-157. doi: 10.1016/j.carbpol.2005.11.004

Cai, X., Tong, H., Shen, X., Chen, W., Yan, J., and Hu, J. (2009). Preparation and characterization of homogeneous chitosan-polylactic acid/hydroxyapatite nanocomposite for bone tissue engineering and evaluation of its mechanical properties. Acta Biomater. 5, 2693-2703. doi: 10.1016/j.actbio.2009.03.005

Calabrese, G., Giuffrida, R., Fabbi, C., Figallo, E., Furno, D. L., Gulino, R., et al. (2016). Collagen-hydroxyapatite scaffolds induce human adipose derived stem cells osteogenic differentiation in vitro. PLOS ONE. 11:e0151181. doi: 10.1371/journal.pone.0151181

Calori, G. M., Mazza, E., Colombo, M., and Ripamonti, C. (2011). The use of bone-graft substitutes in large bone defects: any specific needs? Injury 42:S56. doi: 10.1016/j.injury.2011.06.011

Calvo Guirado, J. L., Ramírez Fernández, M. P., Negri, B., Delgado Ruiz, R. A., Maté Sánchez de-Val, J. E., and Gómez-Moreno, G. (2013). Experimental model of bone response to collagenized xenografts of porcine origin (OsteoBiol $\AA$ mp3): a radiological and histomorphometric study. Clin. Implant. Dent. Relat. Res. 15, 143-151. doi: 10.1111/j.1708-8208.2011.00337.x

Canter, H. I., Vargel, I., Korkusuz, P., Oner, F., Gungorduk, D. B., Cil, B., et al. (2010). Effect of use of slow release of bone morphogenetic protein-2 and transforming growth factor-Beta- 2 in a chitosan gel matrix on cranial bone graft survival in experimental cranial critical size defect model. Ann. Plast. Surg. 64, 342-350. doi: 10.1097/SAP.0b013e3181a73045

Cao, H., and Kuboyama, N. (2010). A biodegradable porous composite scaffold of PGA/ $\beta$-TCP for bone tissue engineering. Bone 46, 386-395. doi: 10.1016/j.bone.2009.09.031

Celikkin, N., Mastrogiacomo, S., Jaroszewicz, J., Walboomers, X. F., and Swieszkowski, W. (2018). Gelatin methacrylate scaffold for bone tissue engineering: the influence of polymer concentration. J. Biomed. Mater. Res A 106, 201-209. doi: 10.1002/jbm.a.36226

Chaloupka, K., Malam, Y., and Seifalian, A. M. (2010). Nanosilver as a new generation of nanoproduct in biomedical applications. Trends. Biotechnol. 28, 580-588. doi: 10.1016/j.tibtech.2010.07.006

Chen, Q., Zhu, C., and Thouas, G. A. (2012). Progress and challenges in biomaterials used for bone tissue engineering: bioactive glasses and elastomeric composites. Prog. Biomater. 1:2. doi: 10.1186/2194-0517-1-2

Chesnutt, B. M., Viano, A. M., Yuan, Y., Yang, Y., Guda, T., Appleford, M. R., et al. (2009). Design and characterization of a novel chitosan/nanocrystalline calcium phosphate composite scaffold for bone regeneration. J. Biomed. Mater. Res. A 88, 491-502. doi: $10.1002 /$ jbm.a.31878

Chieruzzi, M., Pagano, S., Moretti, S., Pinna, R., Milia, E., Torre, L., et al. (2016). Nanomaterials for tissue engineering in dentistry. Nanomaterials 6:E134. doi: 10.3390/nano6070134

Chung, H. J., and Park, T. G. (2007). Surface engineered and drug releasing prefabricated scaffolds for tissue engineering. Adv. Drug Deliv. Rev. 59, 249-262. doi: 10.1016/j.addr.2007.03.015

Clarke, B. (2008). Normal bone anatomy and physiology. Clin. J. Am. Soc. Nephrol. 3:S131. doi: 10.2215/CJN.04151206

Cohen, D. J., Hyzy, S. L., Haque, S., Olson, L. C., Boyan, B. D., Saul, J. M., et al. (2018). Effects of tunable keratin hydrogel erosion on recombinant human bone morphogenetic protein 2 release, bioactivity, and bone induction. Tissue Eng. Part A 24, 1616-1630. doi: 10.1089/ten.TEA.2017.0471

Costa-Pinto, A. R., Correlo, V. M., Sol, P. C., Bhattacharya, M., Srouji, S., Livne, E., et al. (2012). Chitosan-poly(butylene succinate) scaffolds and human bone marrow stromal cells induce bone repair in a mouse calvaria model. J. Tissue Eng. Regen. Med. 6, 21-28. doi: 10.1002/term.391
Cui, Y., Zhu, T., Li, D., Li, Z., Leng, Y., Ji, X., et al. (2019). Bisphosphonatefunctionalized scaffolds for enhanced bone regeneration. Adv. Healthc. Mater. 8:e1901073. doi: 10.1002/adhm.201901073

Currey, J. (1998). "Cortical bone," in Handbook of Biomaterial Properties, eds J. Black and G. Hastings (Boston, MA: Springer), 3-14. doi: 10.1007/978-1-4615-5801-9_1

Da Silva, E. E., Della Colletta, H. H. M., Ferlauto, A. S., Moreira, R. L., Resende, R. R., Oliveira, S., et al. (2009). Nanostructured 3-D collagen/nanotube biocomposites for future bone regeneration scaffolds. Nano Res. 2, 462-473. doi: 10.1007/s12274-009-9042-7

Daculsi, G., Fellah, B. H., Miramond, T., and Durand, M. (2013). Osteoconduction, osteogenicity, osteoinduction, what are the fundamental properties for a smart bone substitutes. IRBM 34, 346-348. doi: 10.1016/j.irbm.2013.07.001

de Vos, P., Lazarjani, H. A., Poncelet, D., and Faas, M. M. (2014). Polymers in cell encapsulation from an enveloped cell perspective. Adv. Drug Deliv. Rev. 67, 15-34. doi: 10.1016/j.addr.2013.11.005

Dhamecha, D., Movsas, R., Sano, U., and Menon, J. U. (2019). Applications of alginate microspheres in therapeutics delivery and cell culture: past, present and future. Int. J. Pharm. 569:118627. doi: 10.1016/j.ijpharm.2019.118627

Di Martino, A., Sittinger, M., and Risbud, M. V. (2005). Chitosan: a versatile biopolymer for orthopaedic tissue-engineering. Biomaterials 26, 5983-5990. doi: 10.1016/j.biomaterials.2005.03.016

Ding, M. (2000). Age variations in the properties of human tibial trabecular bone and cartilage. Acta Orth. Scan. 71(Suppl. 292):1-45. doi: 10.1080/17453674.2000.11744841

Dippold, D., Cai, A., Hardt, M., Boccaccini, A. R., Horch, R., Beier, J. P., et al. (2017). Novel approach towards aligned PCL-Collagen nanofibrous constructs from a benign solvent system. Mater. Sci. Eng. C Mater. Biol. Appl. 72, 278-283. doi: 10.1016/j.msec.2016.11.045

Discher, D. E., Mooney, D. J., and Zandstra, P. W. (2009). Growth factors, matrices, and forces combine and control stem cells. Science 324, 1673-1677. doi: 10.1126/science. 1171643

D’Mello, S., Atluri, K., Geary, S. M., Hong, L., Elangovan, S., and Salem, A. K. (2017). Bone regeneration using gene-activated matrices. AAPS J. 19, 43-53. doi: 10.1208/s12248-016-9982-2

Dobbenga, S., Fratila-Apachitei, L. E., and Zadpoor, A. A. (2016). Nanopatterninduced osteogenic differentiation of stem cells - A systematic review. Acta Biomater. 46, 3-14. doi: 10.1016/j.actbio.2016.09.031

Dong, C., and Lv, Y. (2016). Application of collagen scaffold in tissue engineering: recent advances and new perspectives. Polymers 8:E42. doi: $10.3390 /$ polym 8020042

Donzelli, E., Salvadè, A., Mimo, P., Viganò, M., Morrone, M., Papagna, R., et al. (2007). Mesenchymal stem cells cultured on a collagen scaffold: in vitro osteogenic differentiation. Arch. Oral Biol. 52, 64-73. doi: 10.1016/j.archoralbio.2006.07.007

Dulnik, J., Kołbuk, D., Denis, P., and Sajkiewicz, P. (2018). The effect of a solvent on cellular response to PCL/gelatin and PCL/collagen electrospun nanofibres. Eur. Polym. J. 104, 147-156. doi: 10.1016/j.eurpolymj.2018.05.010

Dutov, P., Antipova, O., Varma, S., Orgel, J. P., and Schieber, J. D. (2016). Measurement of elastic modulus of collagen type I single fiber. PLoS ONE 11:e0145711. doi: 10.1371/journal.pone.0145711

Easterbrook, C., and Maddern, G. (2008). Porcine and bovine surgical products: Jewish, Muslim, and Hindu perspectives. Arch. Surg. 143, 366-370. doi: 10.1001/archsurg.143.4.366

Echave, M. C., Saenz del Burgo, L., Pedraz, J. L., and Orive, G. (2017). Gelatin as biomaterial for tissue engineering. Curr. Pharm. Des. 23, 3567-3584. doi: 10.2174/0929867324666170511123101

Ekaputra, A. K., Prestwich, G. D., Cool, S. M., and Hutmacher, D. W. (2011). The three-dimensional vascularization of growth factor-releasing hybrid scaffold of poly ( $\varepsilon$-caprolactone)/collagen fibers and hyaluronic acid hydrogel. Biomaterials 32, 8108-8117. doi: 10.1016/j.biomaterials.2011.07.022

Fang, L., Leng, Y., and Gao, P. (2006). Processing and mechanical properties of HA/UHMWPE nanocomposites. Biomaterials 27, 3701-3707. doi: 10.1016/j.biomaterials.2006.02.023

Farrell, E., O’Brien, F. J., Doyle, P., Fischer, J., Yannas, I., Harley, B. A., et al. (2006). A collagen-glycosaminoglycan scaffold supports adult rat mesenchymal stem cell differentiation along osteogenic and chondrogenic routes. Tissue Eng. 12, 459-468. doi: 10.1089/ten.2006.12.459 
Farrugia, B. L., Lord, M. S., Whitelock, J. M., and Melrose, J. (2018). Harnessing chondroitin sulphate in composite scaffolds to direct progenitor and stem cell function for tissue repair. Biomater. Sci. 6, 947-957. doi: 10.1039/C7BM01158J

Felician, F. F., Xia, C., Qi, W., and Xu, H. (2018). Collagen from marine biological sources and medical applications. Chem. Biodivers. 15:e1700557. doi: $10.1002 / \mathrm{cbdv} .201700557$

Ferraro, V., Gaillard-Martinie, B., Sayd, T., Chambon, C., Anton, M., and SantéLhoutellier, V. (2017). Collagen type I from bovine bone. Effect of animal age, bone anatomy and drying methodology on extraction yield, self-assembly, thermal behaviour and electrokinetic potential. Int. J. Biol. Macromol. 97, 55-66. doi: 10.1016/j.ijbiomac.2016.12.068

Ferreira, A. M., Gentile, P., Chiono, V., and Ciardelli, G. (2012). Collagen for bone tissue regeneration. Acta Biomater. 8, 3191-3200. doi: 10.1016/j.actbio.2012.06.014

Ficai, A., Andronescu, E., Voicu, G., and Ficai, D. (2011). "Advances in collagen/hydroxyapatite composite materials," in Advances in Composite Materials for Medicine and Nanotechnology, ed B. Attaf (Rijeka: InTechOpen), 1-32. doi: $10.5772 / 13707$

Florczyk, S. J., Leung, M., Li, Z., Huang, J. I., Hopper, R. A., and Zhang, M. (2013). Evaluation of three-dimensional porous chitosan-alginate scaffolds in rat calvarial defects for bone regeneration applications. J. Biomed. Mater. Res. A 101, 2974-2983. doi: 10.1002/jbm.a.34593

Fujita, M., Kinoshita, Y., Sato, E., Maeda, H., Ozono, S., Negishi, H., et al. (2005). Proliferation and differentiation of rat bone marrow stromal cells on poly(glycolic acid)-collagen sponge. Tissue Eng. 11, 1346-1355. doi: $10.1089 /$ ten.2005.11.1346

Gardin, C., Ferroni, L., Favero, L., Stellini, E., Stomaci, D., Sivolella, S., et al. (2012). Nanostructured biomaterials for tissue engineered bone tissue reconstruction. Int. J. Mol. Sci. 13, 737-757. doi: 10.3390/ijms13010737

Garg, T., Singh, O., Arora, S., and Murthy, R. S. R. (2012). Scaffold: a novel carrier for cell and drug delivery. Crit. Rev. Ther. Drug Carrier Syst. 29:1. doi: 10.1615/critrevtherdrugcarriersyst.v29.11.10

Genova, T., Munaron, L., Carossa, S., and Mussano, F. (2016). Overcoming physical constraints in bone engineering: 'the importance of being vascularized'. J. Biomater. Appl. 30, 940-951. doi: 10.1177/0885328215616749

Gentile, P., Chiono, V., Tonda-Turo, C., Ferreira, A. M., and Ciardelli, G. (2011). Polymeric membranes for guided bone regeneration. Biotechnol. J. 6, 1187-1197. doi: 10.1002/biot.201100294

Ghodbane, S. A., and Dunn, M. G. (2016). Physical and mechanical properties of cross-linked type I collagen scaffolds derived from bovine, porcine, and ovine tendons. J. Biomed. Mater. Res. A 104, 2685-2692. doi: 10.1002/jbm.a.35813

Giannoudis, P. V., Dinopoulos, H., and Tsiridis, E. (2005). Bone substitutes: an update. Injury 36:S20. doi: 10.1016/j.injury.2005.07.029

Gorustovich, A. A., Roether, J. A., and Boccaccini, A. R. (2010). Effect of bioactive glasses on angiogenesis: a review of in vitro and in vivo evidences. Tissue Eng. Part B Rev. 16, 199-207. doi: 10.1089/ten.TEB.2009.0416

Granito, R. N., Custódio, M. R., and Rennó, A. C. M. (2016). Natural marine sponges for bone tissue engineering: the state of art and future perspectives. J. Biomed. Mater. Res. B Appl. Biomater. 105, 1717-1727. doi: $10.1002 / j b m . b .33706$

Green, D., Howard, D., Yang, X., Kelly, M., and Oreffo, R. O. (2003). Natural marine sponge fiber skeleton: a biomimetic scaffold for human osteoprogenitor cell attachment, growth, and differentiation. Tissue Eng. 9, 1159-1166. doi: $10.1089 / 10763270360728062$

Grellier, M., Granja, P. L., Fricain, J. C., Bidarra, S. J., Renard, M., Bareille, R., et al. (2009). The effect of the co-immobilization of human osteoprogenitors and endothelial cells within alginate microspheres on mineralization in a bone defect. Biomaterials 30, 3271-3278. doi: 10.1016/j.biomaterials.2009. 02.033

Gross, J., Highberger, J. H., and Schmitt, F. O. (1955). Extraction of collagen from connective tissue by neutral salt solutions. Proc. Natl. Acad. Sci. U.S.A. 41, 1-7. doi: 10.1073/pnas.41.1.1

Guarino, V., Gloria, A., Raucci, M. G., De Santis, R., and Ambrosio, L. (2012). Bioinspired composite and cell instructive platforms for bone regeneration. Int. Mater. Rev. 57, 256-275. doi: 10.1179/0950660812Z.00000000021

Gunatillake, P., Mayadunne, R., and Adhikari, R. (2006). Recent developments in biodegradable synthetic polymers. Biotechnol. Annu. Rev. 12, 301-347. doi: $10.1016 / S 1387-2656(06) 12009-8$
Hadjidakis, D. J., and Androulakis, I. I. (2006). Bone remodeling. Ann. N. Y. Acad. Sci. 1092, 385-396. doi: 10.1196/annals.1365.035

Hamed, E., Jasiuk, I., Yoo, A., Lee, Y., and Liszka, T. (2012). Multi-scale modelling of elastic moduli of trabecular bone. J. R. Soc. Interface 9, 1654-1673. doi: 10.1098/rsif.2011.0814

Hamed, E., Lee, Y., and Jasiuk, I. (2010). Multiscale modeling of elastic properties of cortical bone. Acta Mech. 213, 131-154. doi: 10.1007/s00707-010-0326-5

Hamlekhan, A., Moztarzadeh, F., Mozafari, M., Azami, M., and Nezafati, N. (2011). Preparation of laminated poly( $\varepsilon$-caprolactone)-gelatin-hydroxyapatite nanocomposite scaffold bioengineered via compound techniques for bone substitution. Biomatter 1, 91-101. doi: 10.4161/biom.1.1.17445

Harley, B. A., Leung, J. H., Silva, E. C., and Gibson, L. J. (2007). Mechanical characterization of collagen-glycosaminoglycan scaffolds. Acta Biomater. 3, 463-474. doi: 10.1016/j.actbio.2006.12.009

Harris, L. D., Kim, B. S., and Mooney, D. J. (1998). Open pore biodegradable matrices formed with gas foaming. J. Biomed. Mater. Res. 42, 396-402. doi: 10. 1002/(sici) 1097-4636(19981205)42:3<396::aid-jbm7>3.0.co;2-e

Hemshekhar, M., Thushara, R. M., Chandranayaka, S., Sherman, L. S., Kemparaju, K., and Girish, K. S. (2016). Emerging roles of hyaluronic acid bioscaffolds in tissue engineering and regenerative medicine. Int. J. Biol. Macromol. 86, 917-928. doi: 10.1016/j.ijbiomac.2016.02.032

Hench, L. L. (1998). Bioactive materials: the potential for tissue regeneration. J. Biomed. Mater. Res. 41, 511-518. doi: 10.1002/(sici)10974636(19980915)41:4<511::aid-jbm1>3.0.co;2-f

Heo, D. N., Ko, W. K., Bae, M. S., Lee, J. B., Lee, D. W., Byun, W., et al. (2014), Enhanced bone regeneration with a gold nanoparticle-hydrogel complex. J. Mater. Chem. B 2, 1584-1593. doi: 10.1039/C3TB21246G

Hernández-González, A. C., Téllez-Jurado, L., and Rodríguez-Lorenzo, L. M. (2020). Alginate hydrogels for bone tissue engineering, from injectables to bioprinting: a review. Carbohydr. Polym. 229:115514. doi: 10.1016/j.carbpol.2019.115514

Hiraoka, Y., Kimura, Y. H., and Tabata, Y. (2003). Fabrication and biocompatibility of collagen sponge reinforced with poly(glycolic acid) fiber. Tissue Eng. 9, 1101-1112. doi: 10.1089/10763270360728017

Hollister, S. J. (2005). Porous scaffold design for tissue engineering. Nat. Mater. 4 , 518-524. doi: 10.1038/nmat1421

Holzwarth, J. M., and Ma, P. X. (2011). Biomimetic nanofibrous scaffolds for bone tissue engineering. Biomaterials 32, 9622-9629. doi: 10.1016/j.biomaterials.2011.09.009

Huang, Z. M., Zhang, Y. Z., Ramakrishna, S., and Lim, C. T. (2004). Electrospinning and mechanical characterization of gelatin nanofibers. Polymer 45, 5361-5368. doi: 10.1016/j.polymer.2004.04.005

Huebsch, N., Arany, P. R., Mao, A. S., Shvartsman, D., Ali, O. A., Bencherif, S. A., et al. (2010). Harnessing traction-mediated manipulation of the cell/matrix interface to control stem-cell fate. Nat Mater. 9, 518-526. doi: 10.1038/nmat2732

Hussain, A., Bessho, K., Takahashi, K., and Tabata, Y. (2012). Magnesium calcium phosphate as a novel component enhances mechanical/physical properties of gelatin scaffold and osteogenic differentiation of bone marrow mesenchymal stem cells. Tissue Eng. Part A 18, 768-774. doi: 10.1089/ten.TEA.2011.0310

Iviglia, G., Cassinelli, C., Bollati, D., Baino, F., Torre, E., Morra, M., et al. (2016). Engineered porous scaffolds for periprosthetic infection prevention. Mater. Sci. Eng. C Mater. Biol. Appl. 68, 701-715. doi: 10.1016/j.msec.2016.06.050

Izquierdo-barba, I., Arcos, D., Sakamoto, Y., Terasaki, O., Lopez-Noriega, A., and Vallet-Regí, M. (2008). High-Performance mesoporous bioceramics mimicking bone mineralization. Chem. Mater. 20, 3191-3198. doi: 10.1021/cm800172x

Jahan, K., and Tabrizian, M. (2016). Composite biopolymers for bone regeneration enhancement in bony defects. Biomater. Sci. 4, 25-39. doi: 10.1039/c5bm00163c

Jasiuk, I. M. (2004). "Analysis of trabecular bone as a hierarchical material," in XXI ICTAM (Warsaw), 15-21.

Jiayao, Z., Guanshan, Z., Jinchi, Z., Yuyin, C., and Yongqiang, Z. (2017). Antheraea pernyi silk sericin mediating biomimetic nucleation and growth of hydroxylapatite crystals promoting bone matrix formation. Microsc. Res. Tech. 80, 305-311. doi: 10.1002/jemt.22793

Jin, H. H., Kim, D. H., Kim, T. W., Shin, K. K., Jung, J. S., Park, H. C., et al. (2012). In vivo evaluation of porous hydroxyapatite/chitosan-alginate composite scaffolds for bone tissue engineering. Int. J. Biol. Macromol. 51, 1079-1085. doi: 10.1016/j.ijbiomac.2012.08.027 
Joeris, A., Ondrus, S., Planka, L., Gal, P., and Slongo, T. (2010). ChronOS inject in children with benign bone lesions-Does it increase the healing rate? Eur. J. Pediatr. Surg. 20, 24-28. doi: 10.1055/s-0029-1241866

Kanczler, J. M., Ginty, P. J., White, L., Clarke, N. M. P., Howdle, S. M., Shakesheff, K. M., et al. (2010a). The effect of the delivery of vascular endothelial growth factor and bone morphogenic protein-2 to osteoprogenitor cell populations on bone formation. Biomaterials 31, 1242-1250. doi: 10.1016/j.biomaterials.2009.10.059

Kanczler, J. M., Sura, H. S., Magnay, J., Green, D., Oreffo, R. O., Dobson, J. P., et al. (2010b). Controlled differentiation of human bone marrow stromal cells using magnetic nanoparticle technology. Tissue Eng. Part A 16, 3241-3250. doi: 10.1089/ten.TEA.2009.0638

Kane, R. J., Weiss-bilka, H. E., Meagher, M. J., Liu, Y., Gargac, J. A., Niebur, G. L., et al. (2015). Hydroxyapatite reinforced collagen scaffolds with improved architecture and mechanical properties. Acta Biomater. 17, 16-25. doi: 10.1016/j.actbio.2015.01.031

Kang, S., Park, J. B., Lee, T. J., Ryu, S., Bhang, S. H., La, W. G., et al. (2015). Covalent conjugation of mechanically stiff graphene oxide flakes to three-dimensional collagen scaffolds for osteogenic differentiation of human mesenchymal stem cells. Carbon 83, 162-172. doi: 10.1016/j.carbon.2014.11.029

Katthagen, B., and Mittelmeier, H. (1984). Experimental animal investigation of bone regeneration with collagen-apatite. Arch. Orthop. Trauma Surg. 103, 291-302. doi: 10.1007/bf00432417

Keaveny, T. M. (1998). "Cancellous bone," in Handbook of Biomaterial Properties, eds J. Black and G. Hastings (Boston, MA: Springer), 15-23. doi: 10.1007/978-1-4615-5801-9_2

Khan, F., and Ahmad, S. R. (2013). Polysaccharides and their derivatives for versatile tissue engineering application. Macromol. Biosci. 13, 395-421. doi: 10.1002/mabi.201200409

Khodakaram-Tafti, A., Mehrabani, D., and Shaterzadeh-Yazdi, H. (2017). An overview on autologous fibrin glue in bone tissue engineering of maxillofacial surgery. Dent. Res. J. 14, 79-86.

Khor, E., and Lim, L. Y. (2003). Implantable applications of chitin and chitosan. Biomaterials 24, 2339-2349. doi: 10.1016/s0142-9612(03)00026-7

Kikuchi, M., Ikoma, T., Syoji, D., Matsumoto, H., Koyama, Y., Itoh, S., et al. (2004). Porous body preparation of hydroxyapatite/collagen nanocomposites for bone tissue regeneration. Key Eng. Mater. 254, 561-564. doi: 10.4028/www.scientific.net/KEM.254-256.561

Kikuchi, M., Itoh, S., Ichinose, S., Shinomiya, K., and Tanaka, J. (2001). Self-organization mechanism in a bone-like hydroxyapatite/collagen nanocomposite synthesized in vitro and its biological reaction in vivo. Biomaterials 22, 1705-1711. doi: 10.1016/s0142-9612(00)00305-7

Kim, H. W., Song, J. H., and Kim, H. E. (2005). Nanofiber generation of gelatinhydroxyapatite biomimetics for guided tissue regeneration. Adv. Funct. Mater. 15, 1988-1994. doi: 10.1002/adfm.200500116

Kim, S. K., and Rajapakse, N. (2005). Enzymatic production and biological activities of chitosan oligosaccharides (COS): A review. Carbohydr. Polym. 62, 357-368. doi: 10.1016/j.carbpol.2005.08.012

Kim, Y., Nowzari, H., and Rich, S. K. (2013). Risk of prion disease transmission through bovine-derived bone substitutes: a systematic review. Clin. Implant. Dent. Relat. Res. 15, 645-653. doi: 10.1111/j.1708-8208.2011.00407.x

Kishimoto, N., Momota, Y., Hashimoto, Y., Omasa, T., and Kotani, J. (2011). Self-assembling peptide RADA16 as a scaffold in bone tissue engineering using dedifferentiated fat cells. J. Oral Tissue Eng. 8, 151-161. doi: 10.11223 /jarde.8.151

Kolambkar, Y. M., Boerckel, J. D., Dupont, K. M., Bajin, M., Huebsch, N., Mooney, D. J., et al. (2011). Spatiotemporal delivery of bone morphogenetic protein enhances functional repair of segmental bone defects. Bone 49, 485-492. doi: 10.1016/j.bone.2011.05.010

Kowalczewski, C. J., and Saul, J. M. (2018). Biomaterials for the delivery of growth factors and other therapeutic agents in tissue engineering approaches to bone regeneration. Front. Pharmacol. 9:513. doi: 10.3389/fphar.2018.00513

Kumar, P. (2018). Nano- $\mathrm{TiO}_{2}$ doped chitosan scaffold for the bone tissue engineering applications. Int. J. Biomater. 2018:6576157. doi: 10.1155/2018/6576157

Kuttappan, S., Mathew, D., and Nair, M. B. (2016). Biomimetic composite scaffolds containing bioceramics and collagen/gelatin for bone tissue engineering - A mini review. Int. J. Biol. Macromol. 93, 1390-1401. doi: 10.1016/j.ijbiomac.2016.06.043
La Mantia, F. P., Morreale, M., Botta, L., Mistretta, M. C., Ceraulo, M., and Scaffaro, R. (2017). Degradation of polymer blends: a brief review. Polym. Degrad. Stab. 145, 79-92. doi: 10.1016/j.polymdegradstab.2017.07.011

Lafon, J. P., Champion, E., and Bernache-Assollant, D. (2008). Processing of ABtype carbonated hydroxyapatite $\mathrm{Ca}_{10-x}\left(\mathrm{PO}_{4}\right)_{6-x}\left(\mathrm{CO}_{3}\right)_{x}(\mathrm{OH})_{2-x-2 y}\left(\mathrm{CO}_{3}\right)_{y}$ ceramics with controlled composition. J. Eur. Ceram. Soc. 28, 139-147. doi: 10.1016/j.jeurceramsoc.2007.06.009

Landi, E., Valentini, F., and Tampieri, A. (2008). Porous hydroxyapatite/gelatine scaffolds with ice-designed channel-like porosity for biomedical applications. Acta Biomater. 4, 1620-1626. doi: 10.1016/j.actbio.2008. 05.023

Lara, H. H., Garza-Trevino, E. N., Ixtepan-Turrent, L., and Singh, D. K. (2011). Silver nanoparticles are broad-spectrum bactericidal and virucida compounds. J. Nanobiotechnol. 9:30. doi: 10.1186/1477-3155-9-30

Laurencin, C., Khan, Y., and El-Amin, S. F. (2006). Bone graft substitutes. Expert. Rev. Med. Devices 3, 49-57. doi: 10.1586/17434440.3.1.49

Lee, D., Heo, D. N., Nah, H. R., Lee, S. J., Ko, W. K., Lee, J. S., et al. (2018). Injectable hydrogel composite containing modified gold nanoparticles: implication in bone tissue regeneration. Int. J. Nanomedicine 13, 7019-7031. doi: $10.2147 /$ IJN.S185715

Lee, K. Y., and Yuk, S. H. (2007). Polymeric protein delivery systems. Prog. Polym. Sci. 32, 669-697. doi: 10.1016/j.progpolymsci.2007.04.001

Lee, S. H., and Shin, H. (2007). Matrices and scaffolds for delivery of bioactive molecules in bone and cartilage tissue engineering. Adv. Drug Deliv. Rev. 59, 339-359. doi: 10.1016/j.addr.2007.03.016

León-López, A., Morales-Peñaloza, A., Martínez-Juárez, V. M., Vargas-Torres, A., Zeugolis, D. I., and Aguirre-Álvarez, G. (2019). Hydrolyzed collagensources and applications. Molecules 24:E4031. doi: 10.3390/molecules242 24031

Levengood, S. L., and Zhang, M. (2014). Chitosan-based scaffolds for bone tissue engineering. J. Mater. Chem. B Mater. Biol. Med. 2, 3161-3184. doi: $10.1039 / \mathrm{C} 4 \mathrm{~TB} 00027 \mathrm{G}$

Li, C., Vepari, C., Jin, H. J., Kim, H. J., and Kaplan, D. L. (2006). Electrospun silk-BMP-2 scaffolds for bone tissue engineering. Biomaterials 27, 3115-3124. doi: 10.1016/j.biomaterials.2006.01.022

Li, G., Zhang, T., Li, M., Fu, N., Fu, Y., Ba, K., et al. (2014). Electrospun fibers for dental and craniofacial applications. Curr. Stem Cell Res. Ther. 9, 187-195. doi: 10.2174/1574888X09666140213151717

Li, H., and Chang, J. (2013). Stimulation of proangiogenesis by calcium silicate bioactive ceramic. Acta Biomater. 9, 5379-5389. doi: 10.1016/j.actbio.2012.10.019

Li, J., Sun, H., Sun, D., Yao, Y., Yao, F., and Yao, K. (2011). Biomimetic multicomponent polysaccharide/nano-hydroxyapatite composites for bone tissue engineering. Carbohydr. Polym. 85, 885-894. doi: 10.1016/j.carbpol.2011

Li, X., and Chang, J. (2005). Preparation and characterization of bioactive collagen/wollastonite composite scaffolds. J. Mater. Sci. Mater. Med. 16, 361-365. doi: 10.1007/s10856-005-0636-7

Li, Z., Ramay, H. R., Hauch, K. D., Xiao, D., and Zhang, M. (2005). Chitosan-alginate hybrid scaffolds for bone tissue engineering. Biomaterials 26, 3919-3928. doi: 10.1016/j.biomaterials.2004.09.062

Liao, S., Watari, F., Zhu, Y., Uo, M., Akasaka, T., Wang, W., et al. (2007). The degradation of the three layered nano-carbonated hydroxyapatite/collagen/PLGA composite membrane in vitro. Dent. Mater. 23, 1120-1128. doi: 10.1016/j.dental.2006.06.045

Lin, H., Tang, Y., Lozito, T. P., Oyster, N., Kang, R. B., Fritch, M. R., et al. (2017). Projection stereolithographic fabrication of BMP-2 gene-activated matrix for bone tissue engineering. Sci. Rep. 7:11327. doi: 10.1038/s41598-017-11051-0

Liu, H., Li, H., Cheng, W., Yang, Y., Zhu, M., and Zhou, C. (2006). Novel injectable calcium phosphate/chitosan composites for bone substitute materials. Acta Biomater. 2, 557-565. doi: 10.1016/j.actbio.2006.03.007

Liu, X., and Ma, P. X. (2004). Polymeric scaffolds for bone tissue engineering. Ann. Biomed. Eng. 32, 477-486. doi: 10.1023/b:abme.0000017544.36001.8e

Liuyun, J., Yubao, L., Li, Z., and Jianguo, L. (2008). Preparation and properties of a novel bone repair composite: nanohydroxyapatite/chitosan/carboxymethyl cellulose. J. Mater. Sci. Mater. Med. 19, 981-987. doi: 10.1007/s10856-007-3208-1

Lo, C. M., Wang, H. B., Dembo, M., and Wang, Y. L. (2000). Cell movement is guided by the rigidity of the substrate. Biophys. J. 79, 144-152. doi: 10.1016/S0006-3495(00)76279-5 
Logeart-Avramoglou, D., Anagnostou, F., Bizios, R., and Petite, H. (2005). Engineering bone: challenges and obstacles. J. Cell. Mol. Med. 9, 72-84. doi: 10.1111/j.1582-4934.2005.tb00338.x

Lopes, D., Martins-Cruz, C., Oliveira, M. B., and Mano, J. F. (2018). Bone physiology as inspiration for tissue regenerative therapies. Biomaterials 185 , 240-275. doi: 10.1016/j.biomaterials.2018.09.028

Lu, H., Kawazoe, N., Kitajima, T., Myoken, Y., Tomita, M., Umezawa, A., et al. (2012). Spatial immobilization of bone morphogenetic protein-4 in a collagen-PLGA hybrid scaffold for enhanced osteoinductivity. Biomaterials 33, 6140-6146. doi: 10.1016/j.biomaterials.2012.05.038

Luna, S. M., Silva, S. S., Gomes, M. E., Mano, J. F., and Reis, R. L. (2011). Cell adhesion and proliferation onto chitosan-based membranes treated by plasma surface modification. J. Biomater. Appl. 26, 101-116. doi: $10.1177 / 0885328210362924$

Ma, P. X., and Langer, R. (1998). "Fabrication of biodegradable polymer foams for cell transplantation and tissue engineering," in Tissue Engineering Methods and Protocols, eds M. Yarmush and J. Morgen (Totowa, NJ: Humana Press), 47-56. doi: 10.1385/0-89603-516-6:47

Mackie, E. J. (2003). Osteoblasts: novel roles in orchestration of skeletal architecture. Int. J. Biochem. Cell Biol. 35, 1301-1305. doi: 10.1016/S1357-2725(03)00107-9

Madihally, S. V., and Matthew, H. W. (1999). Porous chitosan scaffolds for tissue engineering. Biomaterials 20, 1133-1142. doi: 10.1016/s0142-9612(99) 00011-3

Man, Y., Wang, P., Guo, Y., Xiang, L., Yang, Y., Qu, Y., et al. (2012). Angiogenic and osteogenic potential of platelet-rich plasma and adiposederived stem cell laden alginate microspheres. Biomaterials 33, 8802-8811. doi: 10.1016/j.biomaterials.2012.08.054

Manda, M. G., da Silva, L. P., Cerqueira, M. T., Pereira, D. R., Oliveira, M. B., Mano, J. F., et al. (2018). Gellan gum-hydroxyapatite composite spongy-like hydrogels for bone tissue engineering. J. Biomed. Mater. Res. A 106, 479-490. doi: $10.1002 /$ jbm.a.36248

Manolagas, S. C. (2000). Birth and death of bone cells: basic regulatory mechanisms and implications for the pathogenesis and treatment of osteoporosis. Endocr. Rev. 21, 115-137. doi: 10.1210/edrv.21.2.0395

Manssor, N. A., Radzi, Z., Yahya, N. A., Mohamad Yusof, L., Hariri, F., Khairuddin, N. H., et al. (2016). Characteristics and Young's modulus of collagen fibrils from expanded skin using anisotropic controlled rate self-inflating tissue expander. Skin Pharmacol. Physiol. 29, 55-62. doi: 10.1159/000431328

Marí-Buyé, N., Luque, T., Navajas, D., and Semino, C. E. (2013). Development of a three-dimensional bone-like construct in a soft self-assembling peptide matrix. Tissue Eng. Part A 19, 870-881. doi: 10.1089/ten.TEA.2012. 0077

Marquis, M. E., Lord, E., Bergeron, E., Drevelle, O., Park, H., Cabana, F., et al. (2009). Bone cells-biomaterials interactions. Front. Biosci. 14, 1023-1067. doi: $10.2741 / 3293$

Marsich, E., Bellomo, F., Turco, G., Travan, A., Donati, I., and Paoletti, S. (2013). Nano-composite scaffolds for bone tissue engineering containing silver nanoparticles: preparation, characterization and biological properties. J. Mater. Sci. Mater. Med. 24, 1799-1807. doi: 10.1007/s10856-013-4923-4

Martins, A., Chung, S., Pedro, A. J., Sousa, R. A., Marques, A. P., Reis, R. L., and Neves, N. M. (2009). Hierarchical starch-based fibrous scaffold for bone tissue engineering applications. J. Tissue Eng. Regen. Med. 3, 37-42. doi: 10.1002/term.132

Martins, A. M., Alves, C. M., Kurtis Kasper, F., Mikos, A. G., and Reis, R. L. (2010). Responsive and in situ-forming chitosan scaffolds for bone tissue engineering applications: an overview of the last decade. J. Mater. Chem. 20, 1638-1645. doi: $10.1039 / \mathrm{B} 916259 \mathrm{~N}$

Mata, A., Geng, Y., Henrikson, K. J., Aparicio, C., Stock, S. R., Satcher, R. L., et al. (2010). Bone regeneration mediated by biomimetic mineralization of a nanofiber matrix. Biomaterials 31, 6004-6012. doi: 10.1016/j.biomaterials.2010.04.013

Matthews, J. A., Wnek, G. E., Simpson, D. G., and Bowlin, G. L. (2002). Electrospinning of collagen nanofibers. Biomacromolecules 3, 232-238. doi: 10.1021/bm015533u

Meinel, L., and Kaplan, D. L. (2012). Silk constructs for delivery of musculoskeletal therapeutics. Adv. Drug Deliv. Rev. 64, 1111-1122. doi: 10.1016/j.addr.2012.03.016
Melke, J., Midha, S., Ghosh, S., Ito, K., and Hofmann, S. (2016). Silk fibroin as biomaterial for bone tissue engineering. Acta Biomater. 31, 1-16. doi: 10.1016/j.actbio.2015.09.005

Meyer, M. (2019). Processing of collagen based biomaterials and the resulting materials properties. Biomed. Eng. Online. 18:24. doi: 10.1186/s12938-019-0647-0

Michael, F. M., Khalid, M., Walvekar, R., Ratnam, C. T., Ramarad, S., Siddiqui, H., et al. (2016). Effect of nanofillers on the physico-mechanical properties of load bearing bone implants. Mater. Sci. Eng. C Mater. Biol. Appl. C 67, 792-806. doi: 10.1016/j.msec.2016.05.037

Minardi, S., Corradetti, B., Taraballi, F., Sandri, M., Van, E. J., Cabrera, F. J., et al. (2015). Evaluation of the osteoinductive potential of a bio-inspired scaffold mimicking the osteogenic niche for bone augmentation. Biomaterials 62, 128-137. doi: 10.1016/j.biomaterials.2015.05.011

Mizuno, M., Fujisawa, R., and Kuboki, Y. (2000). Type I collagen-induced osteoblastic differentiation of bone-marrow cells mediated by collagenalpha 2 beta 1 integrin interaction. J. Cell Physiol. 184, 207-213. doi: 10.1002/1097-4652(200008)184:2<207::AID-JCP8>3.0.CO;2-U

Mohamad Yunos, D., Bretcanu, O., and Boccaccini, A. R. (2008). Polymerbioceramic composites for tissue engineering scaffolds. J. Mater. Sci. 43, 4433-4442. doi: 10.1007/s10853-008-2552-y

Mohamed, S., and Shamaz, B. H. (2015). Bone tissue engineering and bony scaffolds. Int. J. Dent. Oral Heal. 1, 15-20. doi: 10.25141/2471-657X-2015-1.0001

Moosazadeh Moghaddam, M., Bonakdar, S., Shokrgozar, M. A., Zaminy, A., Vali, H., and Faghihi, S. (2019). Engineered substrates with imprinted celllike topographies induce direct differentiation of adipose-derived mesenchymal stem cells into Schwann cells. Artif. Cells Nanomed. Biotechnol. 47, 1022-1035. doi: 10.1080/21691401.2019.1586718

Moshaverinia, A., Chen, C., Akiyama, K., Ansari, S., Xu, X., Chee, W. W., et al. (2012). Alginate hydrogel as a promising scaffold for dental-derived stem cells: an in vitro study. J. Mater. Sci. Mater. Med. 23, 3041-3051. doi: 10.1007/s10856-012-4759-3

Mukherjee, D., Tunkle, A., Roberts, R., Clavenna, A., Rogers, S., and Smith, D. (2003). An animal evaluation of a paste of chitosan glutamate and hydroxyapatite as a synthetic bone graft material. J. Biomed. Mater. Res. Part B Appl. Biomater. 67, 603-609. doi: 10.1002/jbm.b.10050

Murakami, S., Miyaji, H., Nishida, E., Kawamoto, K., Miyata, S., Takita, H., et al. (2017). Dose effects of beta-tricalcium phosphate nanoparticles on biocompatibility and bone conductive ability of three-dimensional collagen scaffolds. Dent. Mater. J. 36, 573-583. doi: 10.4012/dmj.2016-295

Naghieh, S., Badrossamay, M., Foroozmehr, E., and Kharaziha, M. (2017). Combination of PLA micro-fibers and PCL-gelatin nano-fibers for development of bone tissue engineering scaffolds. Int. J. Swarm Int. Evol. Comput. 6, 1-4. doi: 10.4172/2090-4908.1000150

Nair, L. S., and Laurencin, C. T. (2007). Biodegradable polymers as biomaterials. Prog. Polym. Sci. 32, 762-798. doi: 10.1016/j.progpolymsci.2007. 05.017

Nakamichi, Y., Udagawa, N., Suda, T., and Takahashi, N. (2018). Mechanisms involved in bone resorption regulated by vitamin D. J. Steroid Biochem. Mol. Biol. 177, 70-76. doi: 10.1016/j.jsbmb.2017.11.005

Nakaoka, R., Hirano, Y., Mooney, D. J., Tsuchiya, T., and Matsuoka, A. (2013). Study on the potential of RGD- and PHSRN-modified alginates as artificial extracellular matrices for engineering bone. J. Artif. Org. 16, 284-293. doi: 10.1007/s10047-013-0703-7

Nemati, S., Kim, S. J., Shin, Y. M., and Shin, H. (2019). Current progress in application of polymeric nanofibers to tissue engineering. Nano Converg. 6:36. doi: 10.1186/s40580-019-0209-y

Nguyen, B. B., Moriarty, R. A., Kamalitdinov, T., Etheridge, J. M., and Fisher, J. P. (2017). Collagen hydrogel scaffold promotes mesenchymal stem cell and endothelial cell coculture for bone tissue engineering. J. Biomed. Mater. Res A 105, 1123-1131. doi: 10.1002/jbm.a.36008

Nikpour, P., Salimi-Kenari, H., Fahimipour, F., Rabiee, S. M., Imani, M., Dashtimoghadam, E., et al. (2018). Dextran hydrogels incorporated with bioactive glass-ceramic: nanocomposite scaffolds for bone tissue engineering. Carbohydr. Polym. 190, 281-294. doi: 10.1016/j.carbpol.2018.02.083

Niu, L. N., Jiao, K., Qi, Y. P., Nikonov, S., Yiu, C. K., Arola, D. D., et al. (2012). Intrafibrillar silicification of collagen scaffolds for sustained release of stem 
cell homing chemokine in hard tissue regeneration. FASEB J. 26, 4517-4529. doi: $10.1096 /$ fj.12-210211

Nomura, Y., Sakai, H., Ishii, Y., and Shirai, K. (1996). Preparation and some properties of type I collagen from fish scales. Biosci. Biotechnol. Biochem. 60, 2092-2094. doi: 10.1271/bbb.60.2092

Noori, A., Ashrafi, S. J., Vaez-Ghaemi, R., Hatamian-Zaremi, A., and Webster, T. J. (2017). A review of fibrin and fibrin composites for bone tissue engineering. Int. J. Nanomedicine 12, 4937-4961. doi: 10.2147/IJN.S124671

Oftadeh, R., Perez-Viloria, M., Villa-Camacho, J. C., Vaziri, A., and Nazarian, A. (2015). Biomechanics and mechanobiology of trabecular bone: a review. J. Biomech. Eng. 137:0108021. doi: 10.1115/1.4029176

Oh, S. A., Lee, H. Y., Lee, J. H., Kim, T. H., Jang, J. H., Kim, H. W., et al. (2012). Collagen three-dimensional hydrogel matrix carrying basic fibroblast growth factor for the cultivation of mesenchymal stem cells and osteogenic differentiation. Tissue Eng. Part A 18, 1087-1100. doi: 10.1089/ten.TEA.2011.0360

Oliveira, I., Carvalho, A. L., Radhouani, H., Gonçalves, C., Oliveira, J. M., and Reis, R. L. (2018). Promising biomolecules. Adv. Exp. Med. Biol. 1059, 189-205. doi: 10.1007/978-3-319-76735-2_8

Oliveira, J., Rodrigues, M., Silva, S., Malafaya, P., Gomes, M., Viegas, C., et al. (2006). Novel hydroxyapatite/chitosan bilayered scaffold for osteochondral tissue-engineering applications: Scaffold design and its performance when seeded with goat bone marrow stromal cells. Biomaterials 27, 6123-6137. doi: 10.1016/j.biomaterials.2006.07.034

Otsuka, M., Nakagawa, H., Otsuka, K., Ito, A., and Higuchi, W. I. (2013). Effect of geometrical structure on the in vivo quality change of a threedimensionally perforated porous bone cell scaffold made of apatite/collagen composite. J. Biomed. Mater. Res. Part B Appl. Biomater. 101, 338-345. doi: 10.1002/jbm.b.32844

Pang, E. K., Paik, J. W., Kim, S. K., Jung, U. W., Kim, C. S., Cho, K. S., et al. (2005). Effects of chitosan on human periodontal ligament fibroblasts in vitro and on bone formation in rat calvarial defects. J. Periodontol. 76, 1526-1533. doi: 10.1902/jop.2005.76.9.1526

Panzavolta, S., Fini, M., Nicoletti, A., Bracci, B., Rubini, K., Giardino, R., et al. (2009). Porous composite scaffolds based on gelatin and partially hydrolyzed $\alpha$-tricalcium phosphate. Acta Biomater. 5, 636-643. doi: 10.1016/j.actbio.2008

Parenteau-Bareil, R., Gauvin, R., Cliche, S., Gariepy, C., Germain, L., and Berthod, F. (2011). Comparative study of bovine, porcine and avian collagens for the production of a tissue engineered dermis. Acta Biomater. 7, 3757-3765. doi: 10.1016/j.actbio.2011.06.020

Park, D. J., Choi, B. H., Zhu, S. J., Huh, J. Y., Kim, B. Y., and Lee, S. H. (2005). Injectable bone using chitosan-alginate gel/mesenchymal stem cells/BMP-2 composites. J. Craniomaxillofac. Surg. 33, 50-54. doi: $10.1016 /$ j.jcms.2004.05.011

Pati, F., Adhikari, B., and Dhara, S. (2010). Isolation and characterization of fish scale collagen of higher thermal stability. Bioresour. Technol. 101, 3737-3742. doi: 10.1016/j.biortech.2009.12.133

Peng, L., Cheng, X., Zhuo, R., Lan, J., Wang, Y., Shi, B., et al. (2009). Novel gene-activated matrix with embedded chitosan/plasmid DNA nanoparticles encoding PDGF for periodontal tissue engineering. J. Biomed. Mater. Res. A 90, 564-576. doi: 10.1002/jbm.a.32117

Pereira, D. R., Canadas, R. F., Silva-Correia, J., Marques, A. P., Reis, R. L., and Oliveira, J. M. (2013). Gellan gum-based hydrogel bilayered scaffolds for osteochondral tissue engineering. Key Eng. Mater. 587, 255-260. doi: 10.4028/www.scientific.net/KEM.587.255

Peroglio, M., Gremillard, L., Chevalier, J., Chazeau, L., Gauthier, C., and Hamaide, T. (2007). Toughening of bio-ceramics scaffolds by polymer coating. J. Eur. Ceram. Soc. 27, 2679-2685. doi: 10.1016/j.jeurceramsoc.2006.10.016

Pidaparti, R. M., Chandran, A., Takano, Y., and Turner, C. H. (1996). Bone mineral lies mainly outside collagen fibrils: predictions of a composite model for osteonal bone. J. Biomech. 29, 909-916. doi: 10.1016/0021-9290(95)00147-6

Porter, J. R., Ruckh, T. T., and Popat, K. C. (2009). Bone tissue engineering: a review in bone biomimetics and drug delivery strategies. Biotechnol. Prog. 25, 1539-1560. doi: 10.1002/btpr.246

Purohit, S. D., Bhaskar, R., Singh, H., Yadav, I., Gupta, M. K., and Mishra, N. C. (2019). Development of a nanocomposite scaffold of gelatin-alginate-graphene oxide for bone tissue engineering. Int. J. Biol. Macromol. 133, 592-602. doi: 10.1016/j.ijbiomac.2019.04.113
Qiao, P., Wang, J., Xie, Q., Li, F., Dong, L., and Xu, T. (2013). Injectable calcium phosphate-alginate-chitosan microencapsulated MC3T3-E1 cell paste for bone tissue engineering in vivo. Mater. Sci. Eng. C Mater. Biol. Appl. 33, 4633-4639. doi: 10.1016/j.msec.2013.07.022

Qu, Z., Yan, J., Li, B., Zhuang, J., and Huang, Y. (2010). Improving bone marrow stromal cell attachment on chitosan/hydroxyapatite scaffolds by an immobilized RGD peptide. Biomed. Mater. 5:065001. doi: 10.1088/1748-6041/5/6/065001

Quinlan, E., Partap, S., Azevedo, M. M., Jell, G., Stevens, M. M., and O’Brien, F. J. (2015). Hypoxia-mimicking bioactive glass/collagen glycosaminoglycan composite scaffolds to enhance angiogenesis and bone repair. Biomaterials 52, 358-366. doi: 10.1016/j.biomaterials.2015.02.006

Raftery, R., O’Brien, F. J., and Cryan, S. A. (2013). Chitosan for gene delivery and orthopedic tissue engineering applications. Molecules 18, 5611-5647. doi: 10.3390/molecules 18055611

Rai, M., Yadav, A., and Gade, A. (2001). Silver nanoparticles as a new generation of antimicrobials. Biotechnol. Adv. 27, 76-83. doi: 10.1016/j.biotechadv.2008.09.002

Raina, D. B., Qayoom, I., Larsson, D., Zheng, M. H., Kumar, A., Isaksson, H., et al. (2019). Guided tissue engineering for healing of cancellous and cortical bone using a combination of biomaterial based scaffolding and local bone active molecule delivery. Biomaterials 188, 38-49. doi: 10.1016/j.biomaterials.2018.10.004

Raisin, S., Belamie, E., and Morille, M. (2016). Non-viral gene activated matrices for mesenchymal stem cells based tissue engineering of bone and cartilage. Biomaterials 104, 223-237. doi: 10.1016/j.biomaterials.2016.07.017

Rajabi, M., Ali, A., McConnell, M., and Cabral, J. (2020). Keratinous materials: structures and functions in biomedical applications. Mater. Sci. Eng. C Mater. Biol. Appl. 110:110612. doi: 10.1016/j.msec.2019.110612

Rajesh, R., and Ravichandran, Y. D. (2015). Development of a new carbon nanotube-alginate-hydroxyapatite tricomponent composite scaffold for application in bone tissue engineering. Int. J. Nanomedicine 10, 7-15. doi: $10.2147 / I J N . S 79971$

Rao, S. H., Harini, B., Shadamarshan, R. P. K., Balagangadharan, K., and Selvamurugan, N. (2018). Natural and synthetic polymers/bioceramics/bioactive compounds-mediated cell signalling in bone tissue engineering. Int. J. Biol. Macromol. 110, 88-96. doi: 10.1016/j.ijbiomac.2017.09.029

Ratanavaraporn, J., Damrongsakkul, S., Kanokpanont, S., Yamamoto, M., and Tabata, Y. (2011). Osteogenic differentiation of bone-marrow-derived stem cells cultured with mixed gelatin and chitooligosaccharide scaffolds. J. Biomater. Sci. Polym. Ed. 22, 1083-1098. doi: 10.1163/092050610X499050

Reddy, R., and Reddy, N. (2018). Biomimetic approaches for tissue engineering. J. Biomater. Sci. Polym. Ed. 29, 1667-1685. doi: 10.1080/09205063.2018.1 500084

Rehorek, L., Chlup, Z., Meng, D., Yunos, D. M., and Boccaccini, A. R., Dlouhý, I. (2013). Response of $45 S 5$ Bioglass $\AA$ foams to tensile loading. Ceram. Int. 39, 8015-8020. doi: 10.1016/j.ceramint.2013.03.070

Ren, L., Yang, P., Wang, Z., Zhang, J., Ding, C., and Shang, P. (2015). Biomechanical and biophysical environment of bone from the macroscopic to the pericellular and molecular level. J. Mech. Behav. Biomed. Mater. 50, 104-122. doi: 10.1016/j.jmbbm.2015.04.021

Rho, J. Y., Kuhn-Spearing, L., and Zioupos, P. (1998). Mechanical properties and the hierarchical structure of bone. Med. Eng. Phys. 20, 92-102. doi: 10.1016/S1350-4533(98)00007-1

Rockwood, D. N., Gil, E. S., Park, S. H., Kluge, J. A., Grayson, W., Bhumiratana, S., et al. (2011). Ingrowth of human mesenchymal stem cells into porous silk particle reinforced silk composite scaffolds: an in vitro study. Acta Biomater. 7, 144-151. doi: 10.1016/j.actbio.2010.07.020

Roeder, B. A., Kokini, K., Sturgis, J. E., Robinson, J. P., and Voytik-Harbin, S. L. (2002). Tensile mechanical properties of three-dimensional type I collagen extracellular matrices with varied microstructure. J. Biomech. Eng. 124, 214-222. doi: 10.1115/1.1449904

Rosa, N., Simoes, R., Magalhães, F. D., and Marques, A. T. (2015). From mechanical stimulus to bone formation: a review. Med. Eng. Phys. 37, 719-728. doi: 10.1016/j.medengphy.2015.05.015

Sahoo, N. G., Pan, Y. Z., Li, L., and Bin He, C. (2013). Nanocomposites for bone tissue regeneration. Nanomedicine 8, 639-653. doi: 10.2217/nnm.13.44 
Sajesh, K. M., Jayakumar, R., Nair, S. V., and Chennazhi, K. P. (2013). Biocompatible conducting chitosan/polypyrrole-alginate composite scaffold for bone tissue engineering. Int. J. Biol. Macromol. 62, 465-471. doi: 10.1016/j.ijbiomac.2013.09.028

Salamanca, E., Hsu, C. C., Huang, H. M., Teng, N. C., Lin, C. T., and Pan, Y. $\mathrm{H}$., et al. (2018). Bone regeneration using a porcine bone substitute collagen composite in vitro and in vivo. Sci. Rep. 8:984. doi: 10.1038/s41598-018-19629-y

Salamanca, E., Tsai, C. Y., Pan, Y. H., Lin, Y. T., Huang, H. M., Teng, N. C., et al. (2016). In vitro and in vivo study of a novel porcine collagen membrane for guided bone regeneration. Materials 9:E949. doi: 10.3390/ma91 10949

Salehi-Nik, N., Rezai Rad, M., Nazeman, P., and Khojasteh, A. (2017). "Polymers for oral and dental tissue engineering," in Biomaterials for Oral and Dental Tissue Engineering, eds L. Tayebi and K. Moharamzadeh (Oxford: Woodhead Publishing), 25-46. doi: 10.1016/B978-0-08-100961-1.00003-7

Salifu, A. A., Lekakou, C., and Labeed, F. H. (2017). Electrospun oriented gelatinhydroxyapatite fiber scaffolds for bone tissue engineering. J. Biomed. Mater. Res. Part A 105, 1911-1926. doi: 10.1002/jbm.a.36058

Salvadè, A., Belotti, D., Donzelli, E., D’Amico, G., Gaipa, G., Renoldi, G., et al. (2007). GMP-grade preparation of biomimetic scaffolds with osteodifferentiated autologous mesenchymal stromal cells for the treatment of alveolar bone resorption in periodontal disease. Cytotherapy 9, 427-438. doi: 10.1080/14653240701341995

Saravanan, S., Nethala, S., Pattnaik, S., Tripathi, A., Moorthi, A., and Selvamurugan, N. (2011). Preparation, characterization and antimicrobial activity of a bio-composite scaffold containing chitosan/nanohydroxyapatite/nano-silver for bone tissue engineering. Int. J. Biol. Macromol. 49, 188-193. doi: 10.1016/j.ijbiomac.2011.04.010

Sayin, E., Baran, E. T., and Hasirci, V. (2014). Protein-based materials in load-bearing tissue-engineering applications. Regen. Med. 9, 687-701. doi: $10.2217 /$ rme.14.52

Schneider, R. K., Puellen, A., Kramann, R., Raupach, K., Bornemann, J., Knuechel, R., et al. (2010). The osteogenic differentiation of adult bone marrow and perinatal umbilical mesenchymal stem cells and matrix remodelling in three-dimensional collagen scaffolds. Biomaterials 31, 467-480. doi: 10.1016/j.biomaterials.2009.09.059

Sell, S. A., Wolfe, P. S., Garg, K., McCool, J. M., Rodriguez, I. A., and Bowlin, G. L. (2010). The use of natural polymers in tissue engineering: a focus on electrospun extracellular matrix analogues. Polymer 2, 522-553. doi: 10.3390/polym 2040522

Serpooshan, V., Julien, M., Nguyen, O., Wang, H., Li, A., Muja, N., et al. (2010). Reduced hydraulic permeability of three-dimensional collagen scaffolds attenuates gel contraction and promotes the growth and differentiation of mesenchymal stem cells. Acta Biomater. 6, 3978-3987. doi: 10.1016/j.actbio.2010.04.028

Shahidi, F., and Abuzaytoun, R. (2005). Chitin, chitosan, and co products: chemistry, production, applications, and health effects. Adv. Food Nutr. Res. 49, 93-135. doi: 10.1016/S1043-4526(05)49003-8

Shi, C., Yuan, Z., Han, F., Zhu, C., and Li, B. (2016). Polymeric biomaterials for bone regeneration. Ann. Joint. 1:27. doi: 10.21037/aoj.2016.11.02

Shimko, D. A., and Nauman, E. A. (2007). Development and characterization of a porous poly(methyl methacrylate) scaffold with controllable modulus and permeability. J. Biomed. Mater. Res. Part B Appl. Biomater. 80, 360-369. doi: $10.1002 / j$ bm.b.30605

Shirosaki, Y. (2012). Preparation of organic-inorganic hybrids with silicate network for the medical applications. J. Ceram. Soc. Jpn. 120, 555-559. doi: $10.2109 /$ jcersj2.120.555

Shirosaki, Y., Furuse, M., Asano, T., Kinoshita, Y., and Kuroiwa, T. (2018). Skull bone regeneration using chitosan-siloxane porous hybrids-long-term implantation. Pharmaceutics 10:E70. doi: 10.3390/pharmaceutics 10020070

Sionkowska, A., and Kozlowska, J. (2013). Properties and modification of porous 3-D collagen/hydroxyapatite composites. Int. J. Biol. Macromol. 52, 250-259. doi: 10.1016/j.ijbiomac.2012.10.002

Sofi, H. S., Ashraf, R., Beigh, M. A., and Sheikh, F. A. (2018). Scaffolds fabricated from natural polymers/composites by electrospinning for bone tissue regeneration. Adv. Exp. Med. Biol. 1078, 49-78. doi: $10.1007 / 978-981-13-0950-2 \_4$
Somo, S. I., Khanna, O., and Brey, E. M. (2017). Alginate microbeads for cell and protein delivery. Methods Mol. Biol. 1479, 217-224. doi: 10.1007/978-1-4939-6364-5_17

Song, J. H., Kim, H. E., and Kim, H. W. (2008). Production of electrospun gelatin nanofiber by water-based co-solvent approach. J. Mater. Sci. Mater. Med. 19, 95-102. doi: 10.1007/s10856-007-3169-4

Stevens, M. M. (2008). Biomaterials for bone tissue engineering. Mater. Today 11, 18-25. doi: 10.1016/S1369-7021(08)70086-5

Stratton, S., Shelke, N. B., Hoshino, K., Rudraiah, S., and Kumbar, S. G. (2016). Bioactive polymeric scaffolds for tissue engineering. Bioact. Mater. 1, 93-108. doi: 10.1016/j.bioactmat.2016.11.001

Streicher, C., Heyny, A., Andrukhova, O., Haigl, B., Slavic, S., Schüler, C., et al. (2017). Estrogen regulates bone turnover by targeting RANKL expression in bone lining cells. Sci. Rep. 7:6460. doi: 10.1038/s41598-01706614-0

Su, J., Xu, H., Sun, J., Gong, X., and Zhao, H. (2013). Dual delivery of BMP-2 and bFGF from a new nano-composite scaffold, loaded with vascular stents for large-size mandibular defect regeneration. Int. J. Mol. Sci. 14, 12714-12728. doi: 10.3390/ijms140612714

Suárez-González, D., Barnhart, K., Saito, E., Vanderby, R. Jr., Hollister, S. J., and Murphy, W. L. (2010). Controlled nucleation of hydroxyapatite on alginate scaffolds for stem cell-based bone tissue engineering. J. Biomed. Mater. Res. A 95, 222-234. doi: 10.1002/jbm.a.32833

Swetha, M., Sahithi, K., Moorthi, A., Srinivasan, N., Ramasamy, K., and Selvamurugan, N. (2010). Biocomposites containing natural polymers and hydroxyapatite for bone tissue engineering. Int. J. Biol. Macromol. 47, 1-4. doi: 10.1016/j.ijbiomac.2010.03.015

Syahrom, A., Abdul Kadir, M. R., and Abdullah, J., Öchsner, A. (2011). Mechanical and microarchitectural analyses of cancellous bone through experiment and computer simulation. Med. Biol. Eng. Comput. 49, 1393-1403. doi: 10.1007/s11517-011-0833-0

Tachibana, A., Kaneko, S., Tanabe, T., and Yamauchi, K. (2005). Rapid fabrication of keratin-hydroxyapatite hybrid sponges toward osteoblast cultivation and differentiation. Biomaterials 26, 297-302. doi: 10.1016/j.biomaterials.2004.02.032

Taguchi, Y., Amizuka, N., Nakadate, M., Ohnishi, H., Fujii, N., Oda, K. et al. (2005). A histological evaluation for guided bone regeneration induced by a collagenous membrane. Biomaterials 26, 6158-6166. doi: 10.1016/j.biomaterials.2005.03.023

Tampieri, A., Celotti, G., Landi, E., Sandri, M., Roveri, N., and Falini, G. (2003). Biologically inspired synthesis of bone-like composite: self-assembled collagen fibers/hydroxyapatite nanocrystals. J. Biomed. Mater. Res. A 67, 618-625. doi: $10.1002 /$ jbm.a.10039

Tan, A., Romanska, H., Lenza, R., Jones, J. R., Hench, L. L., Polak, J. M., et al. (2003). The effect of $58 \mathrm{~S}$ bioactive sol-gel derived foams on the growth of murine lung epithelial cells. Key Eng. Mater. 240-242, 719-724. doi: 10.4028/www.scientific.net/KEM.240-242.719

Tanaka, E., and van Eijden, T. (2003). Biomechanical behavior of the temporomandibular joint disc. Crit. Rev. Oral Biol. Med. 14, 138-150. doi: $10.1177 / 154411130301400207$

Tang, M., Chen, W., Weir, M. D., Thein-Han, W., and Xu, H. H. (2012). Human embryonic stem cell encapsulation in alginate microbeads in macroporous calcium phosphate cement for bone tissue engineering. Acta Biomater. 8, 3436-3445. doi: 10.1016/j.actbio.2012.05.016

Thein-Han, W. W., and Misra, R. D. (2009). Biomimetic chitosannanohydroxyapatite composite scaffolds for bone tissue engineering. Acta Biomater. 5, 1182-1197. doi: 10.1016/j.actbio.2008.11.025

Tierney, C. M., Jaasma, M. J., and O'Brien, F. J. (2009). Osteoblast activity on collagen-GAG scaffolds is affected by collagen and GAG concentrations. $J$. Biomed. Mater. Res. Part A 91, 92-101. doi: 10.1002/jbm.a.32207

Titorencu, I., Albu, M. G., Nemecz, M., and Jinga, V. V. (2017). Natural polymercell bioconstructs for bone tissue engineering. Curr. Stem Cell Res. Ther. 12, 165-174. doi: 10.2174/1574888X10666151102105659

Torres, A. L., Gaspar, V. M., Serra, I. R., Diogo, G. S., Fradique, R., Silva, A. P., et al. (2013). Bioactive polymeric-ceramic hybrid 3D scaffold for application in bone tissue regeneration. Mater. Sci. Eng. C Mater. Biol. Appl. 33, 4460-4469. doi: 10.1016/j.msec.2013.07.003 
Tresguerres, F. G. F., Torres, J., López-Quiles, J., Hernández, G., Vega, J. A., and Tresguerres, I. F. (2020). The osteocyte: a multifunctional cell within the bone. Ann. Anat. 227:151422. doi: 10.1016/j.aanat.2019.151422

Uebersax, L., Apfel, T., Nuss, K. M., Vogt, R., Kim, H. Y., Meinel, L., et al. (2013). Biocompatibility and osteoconduction of macroporous silk fibroin implants in cortical defects in sheep. Eur. J. Pharm. Biopharm. 85, 107-118. doi: 10.1016/j.ejpb.2013.05.008

Unal, M., Creecy, A., and Nyman, J. S. (2018). The role of matrix composition in the mechanical behavior of bone. Curr. Osteoporos. Rep. 16, 205-215. doi: 10.1007/s11914-018-0433-0

Usui, Y., Aoki, K., Narita, N., Murakami, N., Nakamura, I., Nakamura, K., et al. (2008). Carbon nanotubes with high bone-tissue compatibility and boneformation acceleration effects. Small 4, 240-246. doi: 10.1002/smll.200700670

Vagaská, B., Bacáková, L., Filová, E., and Balík, K. (2010). Osteogenic cells on bio-inspired materials for bone tissue engineering. Physiol. Res. 59, 309-322.

Valente, J. F. A., Valente, T. A. M., Alves, P., Ferreira, P., Silva, A., and Correia, I. J. (2012). Alginate based scaffolds for bone tissue engineering. Mater. Sci Eng. C 32, 2596-2603. doi: 10.1016/j.msec.2012.08.001

Valero, C., Javierre, E., García-Aznar, J. M., and Gómez-Benito, M. J. (2014). A cell-regulatory mechanism involving feedback between contraction and tissue formation guides wound healing progression. PLOS ONE 9:e92774. doi: 10.1371/journal.pone.0092774

Van Den Bulcke, A., Bogdanov, B., De Rooze, N., Schacht, E. H., Cornelissen, M., and Berghmans, H. (2000). Structural and rheological properties of methacrylamide modified gelatin hydrogels. Biomacromolecules 1, 31-38. doi: $10.1021 / \mathrm{bm} 990017 \mathrm{~d}$

Varma, S., Orgel, J. P. R. O., and Schieber, J. D. (2016). Nanomechanics of type I collagen. Biophys. J. 111, 50-56. doi: 10.1016/j.bpj.2016.05.038

Venkatesan, J., Bhatnagar, I., and Kim, S. K. (2014a). Chitosan-alginate biocomposite containing fucoidan for bone tissue engineering. Mar. Drugs 12, 300-316. doi: 10.3390/md12010300

Venkatesan, J., Bhatnagar, I., Manivasagan, P., Kang, K. H., and Kim, S. K. (2015). Alginate composites for bone tissue engineering: a review. Int. J. Biol. Macromol. 72, 269-281. doi: 10.1016/j.ijbiomac.2014.07.008

Venkatesan, J., and Kim, S. K. (2010). Chitosan composites for bone tissue engineering-an overview. Mar. Drugs 8, 2252-2266. doi: 10.3390/md8082252

Venkatesan, J., Nithya, R., Sudha, P. N., and Kim, S. K. (2014b). Role of alginate in bone tissue engineering. Adv. Food Nutr. Res. 73, 45-57. doi: 10.1016/B978-0-12-800268-1.00004-4

Venugopal, J., Prabhakaran, M. P., Zhang, Y., Low, S., Choon, A. T., and Ramakrishna, S. (2010). Biomimetic hydroxyapatite-containing composite nanofibrous substrates for bone tissue engineering. Philos. Trans. A Math. Phys. Eng. Sci. 368, 2065-2081. doi: 10.1098/rsta.2010.0012

Venugopal, J., Vadgama, P., Kumar, T. S. S., and Ramakrishna, S. (2007). Biocomposite nanofibres and osteoblasts for bone tissue engineering. Nanotechnology 18:055101. doi: 10.1088/0957-4484/18/5/055101

Visser, R., Rico-Llanos, G. A., Pulkkinen, H., and Becerra, J. (2016). Peptides for bone tissue engineering. J. Control Release 244, 122-135. doi: 10.1016/j.jconrel.2016.10.024

Wagoner Johnson, A. J., and Herschler, B. A. (2011). A review of the mechanical behavior of $\mathrm{CaP}$ and $\mathrm{CaP} /$ polymer composites for applications in bone replacement and repair. Acta Biomater. 7, 16-30. doi: 10.1016/j.actbio.2010.07.012

Wang, C., Huang, W., Zhou, Y., He, L., He, Z., Chen, Z., et al. (2020). 3D printing of bone tissue engineering scaffolds. Bioact. Mater. 5, 82-91. doi: 10.1016/j.bioactmat.2020.01.004

Wang, J., Wang, L., Zhou, Z., Lai, H., Xu, P., Liao, L., et al. (2016). Biodegradable polymer membranes applied in guided bone/tissue regeneration: a review. Polymers 8:E115. doi: 10.3390/polym8040115

Wang, J., Wu, D., Zhang, Z., Li, J., Shen, Y., Wang, Z., et al. (2015). Biomimetically ornamented rapid prototyping fabrication of an apatitecollagen-polycaprolactone composite construct with nano-micro-macro hierarchical structure for large bone defect treatment. ACS Appl. Mater. Interfaces 7, 26244-26256. doi: 10.1021/acsami.5b08534

Wang, J., Zhou, W., Hu, W., Zhou, L., Wang, S., and Zhang, S. (2011). Collagen/silk fibroin bi-template induced biomimetic bone-like substitutes. J. Biomed. Mater. Res. A 99, 327-334. doi: 10.1002/jbm.a.32602
Wang, Q., Huang, Y., and Qian, Z. (2018). Nanostructured surface modification to bone implants for bone regeneration. J. Biomed. Nanotechnol. 14, 628-648. doi: 10.1166/jbn.2018.2516

Wang, S. F., Shen, L., Zhang, W. D., and Tong, Y. J. (2005). Preparation and mechanical properties of chitosan/carbon nanotubes composites. Biomacromolecules 6, 3067-3072. doi: 10.1021/bm050378v

Wang, X., Gu, Z., Jiang, B., Li, L., and Yu, X. (2016). Surface modification of strontium-doped porous bioactive ceramic scaffolds via poly(DOPA) coating and immobilizing silk fibroin for excellent angiogenic and osteogenic properties. Biomater. Sci. 4, 678-688. doi: 10.1039/c5bm00482a

Wang, X., Zhou, Y., Xia, L., Zhao, C., Chen, L., Yi, D., et al. (2015). Fabrication of nano-structured calcium silicate coatings with enhanced stability, bioactivity and osteogenic and angiogenic activity. Colloids Surf. B Biointerfaces 126:358. doi: 10.1016/j.colsurfb.2014.11.044

Weisgerber, D. W., Erning, K., Flanagan, C. L., Hollister, S. J., and Harley, B. A. (2016). Evaluation of multi-scale mineralized collagen-polycaprolactone composites for bone tissue engineering. J. Mech. Behav. Biomed. Mater. 61, 318-327. doi: 10.1016/j.jmbbm.2016.03.032

Westhrin, M., Xie, M., Olderøy, M. Ø., Sikorski, P., Strand, B. L., and Standal, T. (2015). Osteogenic differentiation of human mesenchymal stem cells in mineralized alginate matrices. PLOS ONE 10:e0120374. doi: 10.1371/journal.pone.0120374

Whang, K., Healy, K. E., Elenz, D. R., Nam, E. K., Tsai, D. C., Thomas, C. H., et al. (1999). Engineering bone regeneration with bioabsorbable scaffolds with novel microarchitecture. Tissue Eng. 5, 35-51. doi: 10.1089/ten.1999.5.35

Whang, K., Thomas, C. H., Healy, K. E., and Nuber, G. (1995). A novel method to fabricate bioabsorbable scaffolds. Polymer 36, 837-842. doi: 10.1016/0032-3861(95)93115-3

Witzler, M., Ottensmeyer, P. F., Gericke, M., Heinze, T., Tobiasch, E., and Schulze, M. (2019). Non-cytotoxic agarose/hydroxyapatite composite scaffolds for drug release. Int. J. Mol. Sci. 20:E3565. doi: 10.3390/ijms20143565

Wood, A., Ogawa, M., Portier, R. J., Schexnayder, M., Shirley, M., and Losso, J. N. (2008). Biochemical properties of alligator (Alligator mississippiensis) bone collagen. Comp. Biochem. Physiol. B Biochem. Mol. Biol. 151, 246-249. doi: 10.1016/j.cbpb.2008.05.015

Wu, C., Zhang, Y., Zhu, Y., Friis, T., and Xiao, Y. (2010). Structureproperty relationships of silk-modified mesoporous bioglass scaffolds. Biomaterials $\quad 31, \quad 3429-3438$. doi: 10.1016/j.biomaterials.2010. 01.061

Xia, L., Yin, Z., Mao, L., Wang, X., Liu, J., Jiang, X., et al. (2016). Akermanite bioceramics promote osteogenesis, angiogenesis and suppress osteoclastogenesis for osteoporotic bone regeneration. Sci. Rep. 6:22005. doi: $10.1038 /$ srep22005

Xia, Z., Yu, X., Jiang, X., Brody, H. D., Rowe, D. W., and Wei, M. (2013). Fabrication and characterization of biomimetic collagen-apatite scaffolds with tunable structures for bone tissue engineering. Acta Biomater. 9, 7308-7319. doi: 10.1016/j.actbio.2013.03.038

Xing, Q., Zhao, F., Chen, S., McNamara, J., Decoster, M. A., and Lvov, Y. M. (2010). Porous biocompatible three- dimensional scaffolds of cellulose microfiber/gelatin composites for cell culture. Acta Biomater. 6, 2132-2139. doi: 10.1016/j.actbio.2009.12.036

Xu, H., and Simon, C. (2005). Fast setting calcium phosphate-chitosan scaffold: mechanical properties and biocompatibility. Biomaterials 26, 1337-1348. doi: 10.1016/j.biomaterials.2004.04.043

Xu, Z., and Lam, M. T. (2018). "Alginate application for heart and cardiovascular diseases," in Alginates and Their Biomedical Applications, eds B. H. A. Rehm and M. F. Moradali (Singapore: Springer), 185-212. doi: 10.1007/978-981-10-6910-9

Xynos, I. D., Edgar, A. J., Buttery, L. D., Hench, L. L., and Polak, J. M. (2001). Gene-expression profiling of human osteoblasts following treatment with the ionic products of Bioglass 4555 dissolution. J. Biomed. Mater. Res. 55, 151-157. doi: 10.1002/1097-4636(200105)55:2<151::aid-jbm1001>3.0.co;2-d

Yang, M., Shuai, Y., Zhang, C., Chen, Y., Zhu, L., Mao, C., et al. (2014). Biomimetic nucleation of hydroxyapatite crystals mediated by Antheraea pernyi silk sericin promotes osteogenic differentiation of human bone marrow-derived mesenchymal stem cells. Biomacromolecules 15, 1185-1193. doi: $10.1021 / \mathrm{bm} 401740 \mathrm{x}$ 
Yang, S. F., Leong, K. F., Du, Z. H., and Chua, C. K. (2002). The design of scaffolds for use in tissue engineering. Part II. Rapid prototyping techniques. Tissue Eng. 8, 1-11. doi: 10.1089/107632702753503009

Yannas, I. V. (2004). "Natural Materials", in Biomaterials Science: an Introduction to Materials in Medicine, eds B. D. Ratner, A. S. Hoffman, F. J. Schoen, and J. E. Lemons (Amsterdam, NL: Elsevier Academic Press), 84-94.

Yao, D., Liu, H., and Fan, Y. (2016). Silk scaffolds for musculoskeletal tissue engineering. Exp. Biol. Med. 241, 238-245. doi: 10.1177/15353702156 06994

Yegappan, R., Selvaprithiviraj, V., Amirthalingam, S., Mohandas, A., Hwang, N. S., and Jayakumar, R. (2019). Injectable angiogenic and osteogenic carrageenan nanocomposite hydrogel for bone tissue engineering. Int. J. Biol. Macromol. 122, 320-328. doi: 10.1016/j.ijbiomac.2018.10.182

Young, S., Wong, M., Tabata, Y., and Mikos, A. G. (2005). Gelatin as a delivery vehicle for the controlled release of bioactive molecules. J. Control Release 109, 256-274. doi: 10.1016/j.jconrel.2005.09.023

Yu, H. S., Won, J. E., Jin, G. Z., and Kim, H. W. (2012). Construction of mesenchymal stem cell-containing collagen gel with a macrochanneled polycaprolactone scaffold and the flow perfusion culturing for bone tissue engineering. Bioresour. Open Access 1, 124-136. doi: 10.1089/biores. 2012.0234

Yunoki, S., Ikoma, T., Monkawa, A., Marukawa, E., Sotome, S., Shinomiya, K., et al. (2007). Three-dimensional porous hydroxyapatite/collagen composite with rubber-like elasticity. Mater. Sci. Eng. C 18, 393-409. doi: $10.1163 / 156856207780425077$

Yunus Basha, R., Sampath Kumar, T. S., and Doble, M. (2015). Design of biocomposite materials for bone tissue regeneration. Mater. Sci. Eng. C Mater. Biol. Appl. 57, 452-463. doi: 10.1016/j.msec.2015.07.016

Zamani, M., Morshed, M., Varshosaz, J., and Jannesari, M. (2010). Controlled release of metronidazole benzoate from poly $\varepsilon$-caprolactone electrospun nanofibers for periodontal diseases. Eur. J. Pharm. Biopharm. 75, 179-185. doi: 10.1016/j.ejpb.2010.02.002

Zang, S., Zhu, L., Luo, K., Mu, R., Chen, F., Wei, X., et al. (2017). Chitosan composite scaffold combined with bone marrow-derived mesenchymal stem cells for bone regeneration: in vitro and in vivo evaluation. Oncotarget 8, 110890-110903. doi: 10.18632/oncotarget.22917

Zeng, J. H., Liu, S. W., Xiong, L., Qiu, P., Ding, L. H., Xiong, S. L., et al. (2018). Scaffolds for the repair of bone defects in clinical studies: a systematic review. J. Orthop. Surg. Res. 13:33. doi: 10.1186/s13018-0180724-2

Zhang, D., Wu, X., Chen, J., and Lin, K. (2017). The development of collagen based composite scaffolds for bone regeneration. Bioact. Mater. 3, 129-138. doi: 10.1016/j.bioactmat.2017.08.004
Zhang, R., and Ma, P. X. (2002). "Processing of polymer scaffolds: Phase separation," in Methods of Tissue Engineering, eds A. Atala and R. Lanza (San Diego, CA: Academic Press), 715-724.

Zhao, N., Wang, X., Qin, L., Zhai, M., Yuan, J., Chen, J., et al. (2016). Effect of hyaluronic acid in bone formation and its applications in dentistry. J. Biomed. Mater. Res. A 104, 1560-1569. doi: 10.1002/jbm.a.35681

Zhao, S., Pinholt, E. M., Madsen, J. E., and Donath, K. (2000). Histological evaluation of different biodegradable and non-biodegradable membranes implanted subcutaneously in rats. J. Craniomaxillofac. Surg. 28, 116-122. doi: $10.1054 /$ jcms.2000.0127

Zheng, H., Bai, Y., Shih, M. S., Hoffmann, C., Peters, F., Waldner, C., et al. (2014). Effect of a $\beta$-TCP collagen composite bone substitute on healing of drilled bone voids in the distal femoral condyle of rabbits. J. Biomed. Mater. Res. Part B Appl. Biomater. 102, 376-383. doi: 10.1002/jbm.b.33016

Zhou, L., Tan, G., Tan, Y., Wang, H., Liao, J., and Ning, C. (2014). Biomimetic mineralization of anionic gelatin hydrogels: effect of degree of methacrylation. RSC Adv. 4, 21997-22008. doi: 10.1039/C4RA02271H

Zhou, Y., Yao, H., Wang, J., Wang, D., Liu, Q., and Li, Z. (2015). Greener synthesis of electrospun collagen/hydroxyapatite composite fibers with an excellent microstructure for bone tissue engineering. Int. J. Nanomedicine 10, 3203-3215. doi: 10.2147/IJN.S79241

Zhu, H., Shen, J., Feng, X., Zhang, H., Guo, Y., and Chen, J. (2010). Fabrication and characterization of bioactive silk fibroin/wollastonite composite scaffolds. Mater. Sci. Eng. C 30, 132-140. doi: 10.1016/j.msec.2009.09.009

Zuo, Y., Liu, X., Wei, D., Sun, J., Xiao, W., Zhao, H., et al. (2015). Photocross-linkable methacrylated gelatin and hydroxyapatite hybrid hydrogel for modularly engineering biomimetic osteon. ACS Appl. Mater. Interfaces 7, 10386-10394. doi: 10.1021/acsami.5b01433

Zuo, Y., Xiao, W., Chen, X., Tang, Y., Luo, H., and Fan, H. (2012). Bottomup approach to build osteon-like structure by cell-laden photocrosslinkable hydrogel. Chem. Commun. 48, 3170-3172. doi: 10.1039/c2cc16744a

Conflict of Interest: The authors declare that the research was conducted in the absence of any commercial or financial relationships that could be construed as a potential conflict of interest.

Copyright (c) 2020 Filippi, Born, Chaaban and Scherberich. This is an open-access article distributed under the terms of the Creative Commons Attribution License (CC $B Y)$. The use, distribution or reproduction in other forums is permitted, provided the original author(s) and the copyright owner(s) are credited and that the original publication in this journal is cited, in accordance with accepted academic practice. No use, distribution or reproduction is permitted which does not comply with these terms. 